\title{
Los requisitos \\ del vicio redhibitorio \\ en la compraventa \\ según el Código Civil \\ chileno-colombiano*
}

\section{Jorge OViedo Albán ${ }^{* \star}$}

Resumen: El presente artículo aborda el estudio de los requisitos que debe presentar el vicio redhibitorio en el contrato de compraventa: graves, ocultos y anteriores al contrato, como supuesto de la acción redhibitoria y de la acción de rebaja de precio, según su regulación en el Código Civil de Chile y Colombia. A partir del estudio de las normas, la doctrina y la jurisprudencia de ambos países, con elementos de derecho comparado, se identifican los problemas recurrentes que se han presentado en casos decididos por los tribunales chilenos y colombianos, así como los aspectos objeto de debate doctrinal surgidos a propósito de cada uno de tales requisitos y las soluciones propuestas.

Palabras clave: Vicios redhibitorios, contrato de compraventa, derecho civil chileno, derecho civil colombiano.

* Fecha de recepción: 28 de agosto de 2015. Fecha de aceptación: 2 I de marzo de 2016.

Para citar el artículo: J. OviEdo Albán, "Los requisitos del vicio redhibitorio en la compraventa según el Código Civil chileno-colombiano", Revista de Derecho Privado, Universidad Externado de Colombia, n. ${ }^{\circ} 3$ o, enero-junio de 2016, I 29 -169. DOI: http://dx.doi.org/ro. I860 I/or 234366. n30.06

* Doctor en Derecho y magíster en Derecho Privado por la Universidad de los Andes, Santiago de Chile, Chile. Abogado y especialista en Derecho Comercial por la Pontificia Universidad Javeriana, Bogotá, Colombia. Profesor de Derecho Civil en la Universidad Sergio Arboleda, Bogotá, Colombia. Contacto: jorge.oviedo@usa.edu.co 


\title{
The Requirements of Redhibitory Vices in the Contract of Sale according to the Chilean-Colombian Civil Code
}

\begin{abstract}
Aвstract: This paper analyzes the requirements that must be present in the redhibitory vices in the contract of sale: serious, hidden and prior to the contract, as alleged in the redhibitory course of action and the action of price reduction according to its regulations in the Chilean and Colombian Civil Code. Based on a study of the rules, doctrine and jurisprudence from both countries and using elements of comparative law, the recurring problems that have arisen in cases decided by Chilean and Colombian courts are identified as well as the subject of doctrinal debate issues arising in connection with each of these requirements and proposed solutions.
\end{abstract}

Keywords: Redhibitory vices, contract of sale, Chilean Civil Law, Colombian Civil Law.

Sumario: Introducción. I. El vicio anterior al contrato. A. Consideraciones generales. B. Preexistencia del vicio en venta de géneros. C. Existencia del vicio en germen. II. La gravedad del vicio. A. Factores para calificar la gravedad del vicio. B. Los defectos que desagradan al comprador. C. La posibilidad de reparación del bien. III. El carácter oculto. A. La conducta exigible al comprador. B. El debate acerca de la intervención de peritos. C. Consideraciones. Iv. La prueba del vicio y sus requisitos. Conclusiones. Bibliografía.

\section{Introducción}

Hace algunos años publiqué un artículo referente al concepto de vicio redhibitorio asumido por la jurisprudencia de Chile y Colombia, en aplicación de las reglas contenidas en el Código Civil que, sobre la base del preparado para Chile por Andrés Bello, ha sido adoptado por ambos países ${ }^{\mathrm{I}}$. En dicho artículo analicé lo que las sentencias de los tribunales tanto de Chile como de Colombia han establecido en cuanto al concepto mismo de "vicio" y a una categorización sistemática del mismo: de conformidad con lo establecido en los artículos i 858 c.c. chileno y i9i 5 c.c. colombiano, la exigencia de que el vicio sea grave, anterior al contrato y oculto configura el supuesto de hecho a partir del cual el comprador

Cfr. Oviedo Albán, J., "Sobre el concepto de vicio redhibitorio en la compraventa. Análisis comparado de la jurisprudencia chilena y colombiana", Revista Chilena de Derecho, v. 37, n. ${ }^{\circ}{ }^{2}$, 2010, 24I-269. Aquel artículo, como el presente, con las debidas adaptaciones, son resultado de la investigación que condujo a la tesis doctoral: Oviedo Albán, J., La garantía por vicios ocultos en la compraventa. Análisis de Derecho Privado chileno y colombiano a la luz de las nuevas tendencias del Derecho de contratos, Santiago de Chile, Universidad de los Andes, 20 r 2, aún no publicada al momento de presentación de este artículo a la Revista. 
puede intentar de forma alternativa la acción redhibitoria -por la cual se busca la rebaja del precio-; esto permitió concluir, entre otras cosas, que los tribunales de Chile y Colombia han asumido de forma coincidente que el supuesto para considerar al bien afectado por un vicio es que este se refiera a defectos físicos de origen interno o externo y que los mismos produzcan el efecto de impedir o reducir el uso natural o pactado de la cosa objeto del contrato de venta, por lo cual el concepto de vicio adoptado es el "funcional".

En esta ocasión procederé al estudio de los requisitos con los cuales deben cumplir los vicios para ser calificados como redhibitorios, de manera que este trabajo resulta una continuación de aquel, con énfasis en los análisis hechos por la doctrina chilena y colombiana, verificando también la forma como han sido asumidos por los tribunales, y contrastándolos a su vez con las tendencias doctrinales y jurisprudenciales del derecho comparado. La presencia de dichos requisitos es lo que determina la viabilidad de las acciones edilicias, pues si fallaren, así la cosa presentare materialmente defectos, estos no darían lugar ni a la rescisión del contrato ni a la rebaja del precio 3 . Estos requisitos, cabe agregar, excluyen la culpa o dolo del vendedor, de forma que para la interposición de la acción redhibitoria o de la de rebaja de precio no importa si el vendedor los conocía o no4.

\section{El vicio anterior al contrato}

Según el num. I de los artículos I 858 c.c. chil. y I9I 5 c.c. col., el vicio que será calificado como redhibitorio debe haber existido al tiempo de la venta. Cabe preguntarse si esta regla opera en todos los casos, como por ejemplo la venta

2 La noción funcional de vicio redhibitorio abarca tanto el uso normal como el particular que a la cosa objeto del contrato de venta le pretende dar el comprador, y por tanto constituye vicio el defecto que la haga inapta o inidónea para el uso al cual este la destina, bien sea el normal o el contractual. Sobre este concepto: Ghestin, J., Conformité et garanties dans la vente (Produits mobiliers), París, LGDJ, I983, I6. GRassi, U., I vizi della cosa venduta nella dottrina dell'errore. Il problema dell'inesatto adempimento, Edizioni Scientifiche Italiane, Napoli, I996, I4. DE VERDA Y Beamonte, J. R., Saneamiento por vicios ocultos. Las acciones edilicias, 2. a ed., Aranzadi, Cizur Menor, 2009, 29-33. Por el contrario, según la noción material o conceptual, para que el vicio sea calificado como redhibitorio tiene que cumplir con dos requisitos: debe tratarse de un defecto, y además por este se debe comprometer el uso normal al que se destina el bien y no el fin que persigue el comprador, impidiéndolo o reduciéndolo de tal forma que si lo hubiese conocido no lo habría comprado o lo hubiera hecho a mucho menos precio. Al adoptar esta concepción se puede distinguir el supuesto de los vicios ocultos de otras hipótesis como la nulidad por error o incumplimiento, que tendría lugar en los eventos en que no se comprometa el uso normal de la cosa, sino su especial destinación.

3 Morales Moreno, A. M., "El alcance protector de las acciones edilicias", Anuario de Derecho Civil, t. xxxIII, f. III, I 980, 632-634.

4 Así lo dice, en Chile, el considerando cuarto de una sentencia de reemplazo de la Corte Suprema: "este régimen de acciones propias de los vicios redhibitorios no exige ni culpa ni dolo por parte del vendedor de la cosa. En otras palabras, no interesa la subjetividad del vendedor, puesto que es suficiente con la mera existencia del vicio". Corte Suprema, i 8 de enero de 20 I I, Causa n. ${ }^{\circ} 3$ I 6/2009, resolución n. ${ }^{\circ} 2775$, n. ${ }^{\circ}$ vlex: 333040450. 
de géneros en que la identificación del bien con el cual el vendedor cumplirá la obligación de entrega no se verificará sino hasta este momento; además de si el vicio debe existir en su totalidad o basta que se dé en germen para poder calificarlo como anterior al contrato. A cada uno de estos aspectos dedicaré los párrafos siguientes, precedidos de algunas consideraciones generales sobre su justificación.

\section{A. Consideraciones generales}

Los vicios deben preexistir al momento de celebración del contrato. Si los defectos surgen de forma posterior no constituyen vicios redhibitorios pues hacen parte de los riesgos que debe asumir el comprador, los cuales, si se trata de cuerpos ciertos, le son trasladados desde el momento de perfeccionamiento del acuerdo (conforme a los arts. I 550 y i 820 c.c. chil.; i 607 y i 876 c.c. col.,) o, en Colombia, al momento de la entrega, si esta es comercial5.

En Colombia así lo asumió la Corte Suprema en fallo de i968, en el que estableció que los defectos alegados no se originaron en vicios ocultos de la casa sino en la deficiente construcción de un edificio contiguo, lo que se desarrolló en un momento posterior a la ejecución del contrato y además no dependía del vendedor ${ }^{6}$. En el mismo sentido las consideraciones de los tribunales chilenos: si los vicios o las causas que los generan son posteriores al contrato, no son redhibitorios. Así se decidió en un caso antiguo a propósito de un contrato de venta de un motor y una trilladora. En su demanda el comprador alegó que la máquina se detenía al utilizarla, y según el concepto de mecánicos, presentado por él mismo, resultaba inservible para el desarrollo del objeto contractual, que era emplear las máquinas en la trilla de sementeras. El demandado contestó señalando que

5 Alessandri Rodríguez, A., De la compra-venta i de la promesa de venta, t. iI, Imprenta litográfica Barcelona, Santiago, i 9 1 8, n. ${ }^{\circ}$ I 355, i 89; Gómez Estrada, C., De los principales contratos civiles, 4. ${ }^{\text {a }}$ ed., Temis, Bogotá, 2008, 92; VÉLEz F., Estudio sobre el Derecho Civil colombiano, t. viı, Imprenta París-América, 2. a ed., corregida y aumentada por Luis Ángel Arango, París, I 926 , i 48; VAlENcia Zea A., Derecho Civil, t. iv, De los contratos, 6. a ed., Temis, Bogotá, i 985, 73; Orti Vallejo, A., La protección del comprador por el defecto de la cosa vendida, Ediciones TAT, Granada, I987, 266. En el artículo I42 c.co. chileno se establece que el momento de transmisión de riesgo en la venta comercial es también el de perfección del contrato. En el Código de Comercio colombiano (arts. 929 y 930) los riesgos son trasladados al comprador en el momento en que se hace la entrega del bien. No obstante, los vicios por los que responde el vendedor son también, como en civil, los que tienen causa anterior al contrato, según establece el artículo 934.

6 Corte Suprema de Justicia, Sala de Casación Civil, i 5 de octubre de ig68, M.P.: Guillermo Ospina Fernández, no publicada. En el caso, la compradora de una casa demandó la rebaja del precio e indemnización de perjuicios dado que con posterioridad a la entrega algunas paredes se empezaron a agrietar y se presentaron deformaciones en puertas, ventanas y hundimiento de pisos, por lo que la casa sólo servía imperfectamente para habitarla. En primera instancia se desestimó la pretensión. El Tribunal Superior de Distrito Judicial de Bogotá confirmó el fallo considerando que los daños no se originaron en vicios ocultos de la casa sino en la deficiente construcción de un edificio contiguo. 
el comprador reconoció previamente la máquina, sirviéndose de un ingeniero, y recibió los bienes sin protesta. Además, afirmó que tales defectos no existían al momento de perfeccionarse la venta, y en caso de haber existido, no darían lugar a la acción redhibitoria pues no cumplían con el requisito de impedir su uso natural ni con el de ser ocultos para el comprador. Según consideró el juzgado de instancia, el demandado demostró que tales bienes funcionaban al momento de celebrarse el contrato pues fueron probados por el comprador. Agregó que conforme a las pruebas testimoniales aducidas al proceso, los vicios se debían a hechos posteriores a la celebración del contrato o a descomposturas ocurridas durante el viaje por mar y tierra. El juzgado declaró sin lugar la demanda y la Corte de Santiago confirmó la sentencia apelada del 2 I de junio de I $884^{[7]}$.

\section{B. Preexistencia del vicio en Venta de géneros}

El numeral.$^{\circ}$ de los artículos $185^{8}$ c.c. chil. y 1915 c.c. col. no plantea distinciones entre cosas de cuerpo cierto y cosas de género, para efectos de establecer el requisito de la preexistencia del vicio oculto al momento de la celebración del contrato.

En Chile, según Alessandri Rodríguez, tratándose de ventas de géneros, el momento que se considera para determinar la existencia del vicio no es el de la celebración del contrato, sino el de la individualización del bien, esto es, en la entrega, y, en el caso de ventas al peso, cuenta o medida, cuando se efectúen dichas operaciones ${ }^{8}$. Igualmente, en Colombia, Gómez Estrada afirma que tratándose de venta de géneros, el momento de transmisión del riesgo no es el de la celebración del contrato sino el de la tradición, por lo cual también los vicios anteriores a ese momento deben ser asumidos por el vendedor. Aunque la regla del numeral I. ${ }^{\circ}$ del artículo i9 5 c.c. no distingue y por ello es imperfecta, agrega el autor, tal anomalía se corrige por vía hermenéutica9.

7 Corte de Santiago, I de octubre de i 884, G. I 884, n. ${ }^{\circ} 2495$, I 569 . Igualmente la misma Corte, en un fallo antiguo a propósito de un contrato de venta de una casa donde el comprador alegó vicios provenientes de la mala construcción del alcantarillado y la falta de cimentos de algunos tabiques. La Corte rechazó la demanda por no tratarse de vicios graves y tampoco originados con anterioridad al contrato. Ver Corte de Santiago, i9 de marzo de i932, RDJ, t. 29, secc. 2. ${ }^{\text {, }}$, 78 .

8 Alessandri Rodríguez, ob. cit., n. ${ }^{\circ}$ I 4I 7, 264 A 265.

9 Gómez Estrada, ob. cit., ro . Del mismo modo, aunque refiriéndose a las ventas mercantiles, Gómez Mejía, J. A., Contratos comerciales, Editorial Kelly, Bogotá, i980, P. 52. También parece asumirlo Cárdenas Mejía, cuando sin decirlo expresamente comenta cuál es la posición de la jurisprudencia colombiana: CÁrdenas Mejía, J. P., "La resolución por problemas de funcionamiento de la cosa en el derecho colombiano: el régimen interno -vicios ocultos y garantía mínima presunta- y el régimen de la compraventa internacional de mercaderías", en La terminación del contrato. Nuevas tendencias del Derecho comparado, José Alberto Gaitán Martínez y Fabricio Mantilla Espinosa (dirs.), Universidad del Rosario, Bogotá, 2007, 233. 
En la doctrina francesa clásica así lo sostuvieron BAUdRY-LACANTINERIE y Saignat. Para estos autores, si la cosa es cierta y determinada, dado que los riesgos son asumidos por el comprador a partir de la venta, desde este momento debe soportar las consecuencias derivadas de los defectos surgidos con posterioridad a dicho instante. Pero esta solución, señalaron, no es aplicable a las ventas de cosas genéricas, de manera que así como los riesgos son trasladados al comprador en el momento de la individualización de la cosa e igualmente el comprador debe proceder a examinarlas, también los vicios por los que responde el vendedor deben ser los anteriores, no al perfeccionamiento del contrato, sino a la individualización del bien que debe entregarse al comprador ${ }^{\mathrm{IO}}$. De igual modo se sigue sosteniendo en Francia por doctrina reciente ${ }^{\mathrm{II}}$.

Esta misma posición ha sido asumida en la doctrina española a fines del siglo xx por Orti Vallejo, para quien el requisito del carácter oculto del vicio al momento de la celebración del contrato debe entenderse de forma diversa en la venta de cosa genérica, señalando que en este caso el momento de asunción de los riesgos no necesariamente coincide con la celebración del contrato, sino con la individualización de la cosa; conclusión que apoya basándose en el artículo I $45^{2}$ párrafo 3 c.c. español que dispone ${ }^{\mathrm{I} 2}$ :

El daño o provecho de la cosa vendida, después de perfeccionado el contrato, se regulará por lo dispuesto en los artículos Io96 y I I 82 .

Esta regla se aplicará a la venta de cosas fungibles hecha aisladamente y por un solo precio, o sin consideración a su peso, número o medida.

Si las cosas fungibles se vendieren por un precio fijado con relación al peso, número o medida no se imputará el riesgo al comprador hasta que se hayan pesado, contado o medido, a no ser que éste se haya constituido en mora.

Tal como señala el autor, ello es así porque en la compraventa de una cosa específica el consentimiento se presta sobre ella, lo que supone el conocimiento previo de la misma por el comprador, mientras en la genérica el consentimiento no se

io Baudry-Lacantinerie, G. y Saignat, L., Traité théorique et pratique de Droit Civil. De la vente et de l'échange, XIx, 3. ${ }^{a}$ ed., Librairie de la société du Recueil J.B. Sirey et du Journal du Palais, Paris, I908, n. ${ }^{\circ} 422,429-430$.

i I Cfr. Alter, M., L'obligation de délivrance dans la vente de meubles corporels, París, LGDJ, I972, 203203. Huet, J., Responsabilité du vendeur et garantie contre les vices cachés, Litec, Paris, I987, 2 I3, nt. I, quien hace referencia a fallos de ese país que así lo han asumido. Gross, B. y Bıнr, Рн., Contrats. Ventes civiles et commerciales, baux d'habitation, baux commerciaux, 2. ${ }^{\mathrm{a}}$ ed., Presses Universitarires de France, Paris, 2002, 22 8. Malaurie, Ph.; Aynès, L. y Gautier, P.-Y., Les contrats spéciaux, en Droit Civil, Philippe Malaurie y Laurent Aynès, 4. ${ }^{\mathrm{a}}$ ed., Defrénois, Lextenso, Paris, 2009, n. ${ }^{\circ} 399,236$.

Orti Vallejo, ob. cit., 249 y $266-267$. 
presta sobre una cosa sino sobre la obligación asumida por el vendedor de entregar un bien de un género determinado, lo que hace que no pueda ser conocido por el comprador sino hasta su especificación ${ }^{13}$.

Esta solución resulta acorde con lo propuesto por la doctrina mercantilista contemporánea española, la cual comentando los artículos 336 y 33 I c.co. de ese país afirma que el vendedor extrae las cosas de las del género al que pertenecen en la entrega, por lo que el riesgo (y por ende la responsabilidad por los vicios) no se transmiten sino desde el momento de la misma ${ }^{14}$. De idéntica manera se ha pronunciado la doctrina en el derecho italiano ${ }^{15}$.

En el Código Civil chileno-colombiano esta regla está consagrada en los artículos I 82 I chileno y I 877 colombiano, norma según la cual:

Si se vende una cosa de las que suelen venderse a peso, cuenta o medida, pero señalada de modo que no pueda confundirse con otra porción de la misma cosa, como todo el trigo contenido en cierto granero, la pérdida, deterioro o mejora pertenecerá al comprador, aunque dicha cosa no se haya pesado, contado ni medido, con tal que se haya ajustado el precio.

Si de las cosas que suelen venderse a peso, cuenta o medida, sólo se vende una parte indeterminada, como diez hectolitros de trigo de los contenidos en cierto granero, la pérdida, deterioro o mejora no pertenecerá al comprador, sino después de haberse ajustado el precio y de haberse pesado, contado o medido dicha parte.

Esta posición también ha sido asumida en Colombia por la Corte Suprema de Justicia en sentencia del 15 de octubre de 1968, en la que consideró:

Según los términos del numeral I. ${ }^{\circ}$ del artículos [sic] transcrito, el vicio o vicios redhibitorios han de existir al tiempo de la venta, lo que debe entenderse, desde luego, respecto de los contratos que vercen [sic] sobre especies o cuerpos ciertos que han de quedar determinados como tales en ese momento (art. I 5 I 8), pero en relación con los que se refieren a cosas de género cuya singularización como objeto de estos contratos se realiza en el momento de la tradición de las mismas, o en un tiempo intermedio entre éstas y la celebración del contrato, como cuando se vende cierta cantidad materialmente indeterminada de lo que se suele vender

i 3 Orti Vallejo, ob. cit., 249.

i Cfr. Orti Vallejo, ob. cit., 269.

I5 Greco P. y Cottino, G., Vendita, Commentario del Codice Civile a cura di A. Sciajola e G. Branca, Libro quarto: obbligazioni artt. I470-I 547, 2. ${ }^{a}$ ed., Zanichelli, Roma, I98 I, 250. Luminoso, A., La compravendita, 6 . $^{\mathrm{a}}$ ed., Giappichelli, Torino, 2009, 285 , señala que es un tema aceptado de forma incontrovertida por la doctrina y la jurisprudencia italianas. 
a peso, cuenta o medida, hipótesis en la cual el objeto específico de la negociación no sólo implica el ajuste del precio sino el llevarse a cabo el peso, cuenta o medida, o cuando se vende cabida determinada a tomar de predio cierto, caso en el cual el cumplimiento de la obligación del vendedor también supone la mensura y la especificación escrituraria de la porción en que ha de traducirse el objeto del contrato, etc. En estos otros eventos, el vicio se refiere al momento de la singularización del objeto del contrato ${ }^{16}$.

En conclusión, considero que es posible asumir que a pesar de que el numeral I. ${ }^{\circ}$ de los artículos i 858 c.c. chil. y i 9 I 5 c.c. col. establece que el vicio redhibitorio debe haber existido al tiempo de la venta, la norma se aplica solamente para cuando la cosa objeto del contrato es de especie o cuerpo cierto, no cuando es de género, pues en este caso será el momento de individualización del bien, a la entrega de la cosa, el que servirá para delimitar la preexistencia del mismo. Hay bases normativas para asumir esta posición en el derecho chileno-colombiano, además de que así también lo ha decidido la jurisprudencia de los dos países, por lo que no procede una interpretación y aplicación meramente exegética de la norma mencionada.

\section{Existencia del vicio en germen}

Las normas sobre vicios ocultos no hacen distinciones respecto de si el vicio debe existir en su totalidad al momento de la celebración del contrato o si basta que se haya presentado la causa para su desarrollo.

En España, Verda y BeAmonte señala, con base en fallos de su país que así lo han decidido, que basta la predisposición a que el vicio se desarrolle según el normal desenvolvimiento de las cosas para que el comprador pueda interponer las acciones edilicias. Así, una sentencia del Tribunal Supremo citada por el autor decidió un caso originado en una demanda por la rebaja de precio instaurada por el comprador de una finca alegando como vicio redhibitorio que el bien había sido construido con cemento aluminoso que afectaba la estabilidad de la construcción. El Tribunal, como la sentencia recurrida, consideró que sí se trataba de un vicio redhibitorio pues el defecto constituía un peligro potencial que sólo se podía evitar mediante la reparación o sustitución de la estructura, lo cual significaba que el comprador debía realizar reparaciones periódicas para conservar el bien $^{17}$. También en Francia y en Italia se ha admitido que el vicio puede existir

I6 Corte Suprema de Justicia, I 5 de octubre de i968, cit.

I 7 Verda y Beamonte, ob. cit., p. I24. STS I 7 de octubre de 2005 (RJ 2005, 8593), citado por el autor, quien además hace referencia a otros fallos en el mismo sentido. Verda y Beamonte, ob. cit., I 24-I 26. También lo habían sostenido anteriormente ORTI VAllejo, ob. cit., P. 27 I, y BADEnes Gasset, R., El contrato de compraventa, t. I, 3. ${ }^{a}$ c, José María Bosch editor, Barcelona, I995, 
en germen así se manifieste posteriormente para que pueda cumplirse con el requisito de anterioridad del mismo $^{18}$.

La jurisprudencia chilena ha adoptado la misma posición. Así, en un fallo antiguo de la Corte de Santiago ya citado, del ig de agosto de i884, referente a la rescisión de un contrato de venta de una pareja de caballos, se estableció que la enfermedad de uno de los equinos, que fue el vicio oculto alegado, no se había presentado totalmente pues era de lento desarrollo, así ya al momento de celebración del contrato el caballo afectado presentaba una rasmilladura. También en un caso reciente, la Corte de Apelaciones de Santiago señaló que basta la existencia del vicio en germen al momento de la venta, aunque sólo después se manifieste en toda su gravedad, en un caso relativo a una demanda en que se exigía rebaja de precio por vicios ocultos en un inmueble consistentes en una plaga de termitas, de cuya existencia se podían derivar daños importantes o estructurales en las viviendas afectadas que resultarían inhabilitantes o impedientes de su uso natural, obligando a costosos tratamientos de control y prevención de daños ocultos o ulteriores ${ }^{19}$.

En conclusión, considero que es posible asumir que para la verificación del requisito del vicio de ser anterior al contrato no se requiere que este se haya desarrollado en su totalidad. Basta que con anterioridad a la celebración del contrato, si la cosa fuere un cuerpo cierto, o al momento de su determinación, si fuere de géneros, conforme a lo anotado, exista al menos el germen del vicio oculto o la potencialidad del mismo para desarrollarse y manifestarse con posterioridad al contrato y la entrega del bien.

\section{LA GRAVEDAD DEL VICIO}

Según lo establece el n. ${ }^{\circ} 2$ de los artículos I 858 c.c. chil. y i9 5 c.c. col., son vicios redhibitorios los que, además de ser anteriores al contrato y ocultos, deben:

p. 653 y en doctrina reciente: Herbosa Martínez, I., El contrato de compraventa civil, CivitasThomson Reuters, Cizur Menor, 2013,2 I 2.

i 8 Cfr. Bénabent, A., Droit Civil. Les contrats spéciaux civils et commerciaux, 9 éd., Montcherestien Lextenso éditions, Paris, 20 i i, n. ${ }^{\circ}$ 360, p. i6i; Collart Dutilleul, F. y Delebecque, Ph., Contrats civils et commerciaux, 8. ${ }^{\mathrm{a}}$ ed., Dalloz, Paris, 2007, n. ${ }^{\circ} 27 \mathrm{I}, 239$, con referencia a fallos que así lo han admitido. Bianca, C. M., "La vendita e la permuta", en Trattato di Diritto civile italiano,

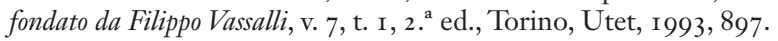

I9 Corte de Apelaciones de Santiago, i6 de marzo de 20 г 2, Rol 7600-20 Io, n. ${ }^{\circ}$ Legal Publishing: $\mathrm{CL} / \mathrm{JUR} / 62 \mathrm{I} / 202_{2}$, relativo a una demanda de rebaja de precio de la venta de inmuebles, que fue acogida, en razón de la presencia de una plaga de termitas, en que se demostró que el vicio era anterior al contrato, oculto y grave. En el considerando io. ${ }^{\circ}$ de este fallo se señala además que no habiéndose definido en el Código de Bello el concepto de vicio redhibitorio, debe entenderse por tal la mala calidad, defecto o daño físico en las cosas, apoyándose en el diccionario de la lengua, sin importar si fueron originados por la naturaleza o por el hecho del hombre. En contra de esta decisión se dedujo recurso de casación en el fondo que fue rechazado por la Corte Suprema. Corte Suprema, 4 de octubre de 2012, Rol 3740-201 2, n. ${ }^{\circ}$ Legal Publishing: CL/JUR/2 I 86/20I 2. 
Ser tales, que por ellos la cosa vendida no sirva para su uso natural, o sólo sirva imperfectamente, de manera que sea de presumir que conociéndolos el comprador no la hubiera comprado o la hubiera comprador a mucho menos precio.

Los autores suelen denominar "grave" al requisito del vicio consistente en la medida en que debe afectar el uso de la cosa, y se trata de la exigencia nuclear para que el defecto del bien llegue a tener el calificativo de vicio redhibitorio ${ }^{20}$. Sobre este punto cabe indagar por los factores seguidos por la doctrina y la jurisprudencia para determinar la gravedad o no de los vicios y, por ende, para calificarlos como redhibitorios. Por ejemplo surgen las inquietudes sobre si la posibilidad o no de reparación del bien determina que el vicio sea grave y además, tal vez como consecuencia de ello, si se exige la total inutilidad del bien.

\section{A. FACtores Para CAlificar la gRAVEDAD DEL Vicio}

El requisito de la gravedad del mismo hace alusión a la forma como este incide en el uso normal o convenido de la cosa de tal manera que la misma resulta inidónea. Es lo que la doctrina ha denominado "relevancia" del vicio, en el sentido de hacerla impropia o disminuir dicho uso, según la fórmula empleada por algunas disposiciones normativas, tal como sucede en el artículo I 484 c.c. de España o en los artículos I 858 número 2 c.co. chil. y I9I 5 número 2 c.c. col. ${ }^{21}$.

Para Verda y Beamonte incluso en casos en que la cosa tuviere un defecto, si este no afecta el uso para el cual el comprador la adquirió, no es que dicho defecto carezca de la gravedad suficiente para dar lugar al ejercicio de las acciones edilicias, sino que ni siquiera merecerá la calificación de vicio ${ }^{22}$. Siguiendo esta

20 Cottin, E., La définition du vice caché dans la vente. Étude de Droit comparé, París, LGDJ, I940, I49; Huet, J., "Les principaux contrats spéciaux", en Traité de Droit Civil sous la direction de facques Ghestin, 2. éd., Paris, LGDJ, 200I, n. ${ }^{\circ}$ I 32 I , 28 I; Rubino, D., "La compravendita", en Trattato di Diritto Civile e Commerciale diretto dai professori Antonio Cicu; Francesco Messineo, v. xxIII, Giuffrè, Milano, I97 I , 775; García Pérez, C. L., "Artículo I484", en Comentarios al Código Civil, t. vir (arts. I 265 a I484), Rodrígo Bercovitz Rodríguez-Cano (dir.), Tirant lo Blanch, Valencia, 20 I3, I0530.

2 I Morales Moreno, "El alcance protector de las acciones edilicias", cit., 633. Morales Moreno, A. M., "Artículo I484", en Comentario del Código Civil, v. iI, Candido Paz-Ares Rodríguez; Rodrígo Bercovitz; Luis Díez-Picazo Ponce de León; Pablo Salvador Coderch (dirs.), Madrid, Ministerio de Justicia, I99 I, 956; Orti VAllejo, ob. cit., 274-275. Este autor ha propuesto superar la calificación del vicio como "grave", y más bien sustituirla por la de relevante o no relevante. Los vicios relevantes corresponderían a los no tolerables según los usos o el pacto entre las partes, y los segundos, a los tolerables según los usos. En otra parte de su libro dice que la gravedad (o relevancia) deberá calificarse conforme al criterio de la función, uso o destino para el que se adquiere el bien. Orti Vallejo, ob. cit., 275 y 403.

Verda y Beamonte, ob. cit., i38, nt. 6. 
posición, Aguayo ha señalado que la gravedad del vicio debe limitarse a la acción redhibitoria y no cabe en la quanti minoris ${ }^{2}$.

En contra de la opinión de Verda y Beamonte, considero que en dicho evento la cosa sí tendrá un vicio, pero este no puede ser calificado como relevante, es decir, no tendrá la calidad de "redhibitorio", si bien ello no significa que el comprador esté desprovisto de acción para defender sus intereses ${ }^{24}$. Lo que corresponde aclarar entonces es de qué forma debe verificarse la relevancia del vicio, esto es, de qué modo el vicio afecta el uso de la cosa para que sea considerado más o menos grave, tema al cual dedicaremos los siguientes párrafos.

En Colombia, Pérez Vives ha enfatizado en dos variables a partir de las cuales se estructura tal requisito: o bien por los vicios la cosa se hace impropia, se disminuye su idoneidad, o bien se inhabilita o disminuye el uso al que la destina el comprador ${ }^{25}$. De idéntica forma, en Chile, Alessandri Rodríguez, al afirmar que en dos casos el vicio puede ser grave: cuando por él la cosa no sirve para su uso natural y cuando sólo sirve imperfectamente ${ }^{26}$. En la doctrina chilena moderna, VIDAL Olivares ha relacionado dicho requisito con la utilidad perseguida por el comprador y, apoyándose en el concepto de incumplimiento esencial, indica que el defecto es grave o importante cuando hace desaparecer la utilidad del contrato o cuando priva al comprador de aquello que tenía derecho a esperar en virtud del mismo 27 .

A mi modo de ver, en la calificación de la gravedad del vicio incidirá si se asume una noción material o una funcional. Así entonces, si la cosa presentare defectos que impiden el uso particular, al seguir la noción material el comprador no podría interponer las acciones edilicias, pero con la funcional sí estaría evidentemente facultado para ello. Por ejemplo, el ya aludido caso planteado por los autores clásicos franceses del contrato de venta del cuadro que el comprador asume como de autoría de un pintor famoso pero que en realidad resulta ser

23 Aguayo J., Las manifestaciones y garantías en el Derecho de contratos español, Civitas-Thomson Reuters, Pamplona, 201 I, 363 .

24 En España, Morales Moreno ha señalado ya que la exigencia de la gravedad del vicio se requiere tanto para la acción redhibitoria como para la quanti minoris. Morales Moreno, "El alcance protector de las acciones edilicias”, cit., 633. En igual sentido Herbosa Martínez, ob. cit., 2 I4.

25 Pérez Vives, A., Compraventa y permuta en Derecho colombiano, 2. ${ }^{\text {a }}$ ed., Temis, Bogotá, i953, n. ${ }^{\circ}$ 33 I, 366 .

26 Alessandri Rodríguez, ob. cit., n. ${ }^{\circ}$ I 422 , 270.

27 Vidal Olivares, A., La protección del comprador. Régimen de la Convención de Viena y su contraste con el Código Civil, Ediciones Universitarias de Valparaíso, Pontificia Universidad Católica de Valparaíso, Valparaíso, 2006, I 78. En igual sentido en Vidal Olivares, A. V., "El incumplimiento de obligaciones con objeto fungible y los remedios del acreedor afectado. Una relectura de las disposiciones del 'Código Civil' sobre incumplimiento", en El Código Civil de Chile (I855-2005). Trabajos expuestos en el congreso internacional celebrado para conmemorar su promulgación (Santiago, 2-6 de octubre de 2005), Alejandro Guzmán Brito (editor científico), 2. a ed., Santiago, Legal Publishing, 2009, 5 I 7 . 
apócrifo; de conformidad con la noción material adoptada por aquellos, debe ser resuelto por las acciones de nulidad al configurarse error, mientras que, conforme a la noción funcional, sí daría lugar a acciones edilicias por tratarse de un vicio oculto. Como consecuencia de ello también podemos afirmar que si el defecto no compromete el uso o si están ausentes calidades no esenciales para el comprador, el vicio no cumple con el requisito de gravedad para ser calificado como redhibitorio, y por tanto el comprador deberá soportarlo o, a lo sumo, le dará derecho a la rebaja de precio $^{28}$.

En España, Verda y Beamonte echa de menos, conforme a la normatividad de ese país, que en los casos de vicios que no puedan ser calificados como graves en los términos anteriores, el comprador no tenga la posibilidad de pedir la rebaja de precio, negativa que califica como "difícil de explicar", afirmando que tal falencia se origina en la falta de armonía entre los artículos I 484 y I 486 c.c.; además de que algunos autores, como aquí ya lo destacamos, mencionan la gravedad como requisito tanto de la acción redhibitoria como de la de rebaja de precio ${ }^{29}$. A partir de ello, el autor propone una interpretación correctora del tenor literal del artículo I 484 c.c. sugiriendo que cuando el vicio no sea grave quepa de todos modos la rebaja del precio, esto basándose en los postulados de Domat, uno de los autores que influenció la redacción del artículo I64I c.c. francés ${ }^{30}$.

Según el autor, el artículo r64I del Code, equivalente al i484 c.c. español, está basado en el pensamiento de Domat, al tiempo que el i644, equivalente al i 486 español, lo está en el de Pothier. Para Verda y Beamonte ese es el origen de la falta de sintonía entre los dos artículos, pues mientras en este último no se permite la utilización de la acción redhibitoria o la de rebaja de precio según que el vicio sea grave o leve, en la interpretación del primero sí se debe permitir tal graduación, puesto que Domat, autor inspirador de la redacción de aquella norma, sí lo admitía ${ }^{3}$. En efecto, al exponer la redhibición, afirmó su procedencia cuando los vicios consisten en defectos que hacen la cosa absolutamente inútil al uso al cual se destina, o disminuyen o hacen incómodo dicho uso, de forma que

28 Cottin, ob. cit., I 5 O.

29 Verda y Beamonte, ob. cit., i 39. En el sentido anotado: Morales Moreno, "El alcance protector de las acciones edilicias", cit., 633. Las normas citadas disponen: artículo I484: "El vendedor estará obligado al saneamiento por los defectos ocultos que tuviere la cosa vendida, si la hacen impropia para el uso a que se la destina, o si disminuyen de tal modo este uso que, de haberlos conocido el comprador, no la habría adquirido o habría dado menos precio por ella; pero no será responsable de los defectos manifiestos o que estuvieren a la vista, ni tampoco de los que no lo estén, si el comprador es un perito que, por razón de su oficio o profesión, debía fácilmente conocerlos"; artículo I486: "En los casos de los dos artículos anteriores, el comprador podrá optar entre desistir del contrato, abonándosele los gastos que pagó, o rebajar una cantidad proporcional del precio, a juicio de peritos. Si el vendedor conocía los vicios o defectos ocultos de la cosa vendida y no los manifestó al comprador, tendrá éste la misma opción y además se le indemnizará de los daños y perjuicios, si optare por la rescisión”.

Verda y BeAmonte, ob. cit., I 56.

3 I Verda y Beamonte, ob. cit., I 56 - I 58. 
si el comprador los hubiere conocido no habría comprado o lo habría hecho a un precio más bajo, dejando a los usos si los hubiere o a la prudencia del juez la determinación de si cabe la resolución o la rebaja del precio ${ }^{32}$.

Por lo anterior, el autor sugiere distinguir entre "vicio relevante" y "vicio redhibitorio". La calificación de vicio relevante queda para todo defecto oculto y anterior a la celebración del contrato, conforme al artículo I484 c.c. español, mientras la de vicio redhibitorio se reserva para los defectos graves al punto de que por ellos se inutiliza la cosa, y darían lugar a la acción redhibitoria o de rebaja de precio. La implicación práctica de tal distinción consiste en que si el vicio es relevante pero no redhibitorio, el comprador tiene derecho a una protección, como ya lo mencionamos, con la acción de rebaja de precio33.

De una forma similar, ORTI VAlLejo propone que conforme a lo dispuesto en los artículos I 484 y I 486 c.c. español, la acción de rebaja de precio quedaría para los casos en que el defecto no impidiese obtener satisfacción ${ }^{34}$. Serrano Chamorro también se pronuncia en un sentido parecido al señalar que no hay una concepción unitaria del supuesto de hecho de las acciones edilicias, siendo redhibitorios, y por tanto dan lugar a acción redhibitoria, los vicios que impiden la utilidad de la cosa, mientras que los que solo la disminuyen dan lugar a rebaja de precio ${ }^{35}$. Aguayo lo propone de modo similar al afirmar que tal solución es coherente con las regulaciones sobre falta de conformidad, además de que lo contrario sería desproteger al comprador que, aunque de forma no grave ve frustrado su interés, continúa interesado en mantener el contrato ${ }^{36}$.

No comparto esta opinión, puesto que los artículos I 484 y I 486 c.c. español dan la alternativa para el comprador (al igual que el Código chileno-colombiano) de interponer ya sea la acción redhibitoria o la de rebaja de precio tanto en el supuesto en que el vicio haga impropia la cosa para el uso a que se destina, en el sentido de impedirlo, o lo disminuya de tal modo que el comprador no la habría adquirido o lo habría hecho a menos precio. Además, la dificultad mencionada por los autores citados no existe en el Código Civil. En efecto, también para el caso en que los vicios no tengan la calidad de "graves", el Código, en norma cuya originalidad la doctrina atribuye a BeLLo, le reserva al comprador la posibilidad de interponer la acción de rebaja de precio37. Así lo establecen los artículos I 868 c.c. chil. y 1925 c.c. col.:

32 Domat, J., Les loix civiles dans leur ordre naturale, t. I, Paris, Chez Nyon Ainé Libraire, I 777, secc. XI, III, 77.

33 Verda y Beamonte, ob. cit., i 58-i 59. Antonio Borrell y Soler, El contrato de compraventa según el Código Civil español, Barcelona, Bosch, 1952, I46.

34 Orti Vallejo, ob. cit., 276.

35 Serrano Chamorro, M. E., Entrega de cosa distinta a la pactada, Cizur Menor, Thomson Aranzadi, 2006, г9०.

36 Aguayo, ob. cit., 363 .

37 Cfr. Alessandri Rodríguez, ob. cit., n. ${ }^{\circ}$ I 424, 274. 
Si los vicios ocultos no son de la importancia que se expresa en el número $2 .^{\circ} \mathrm{del}$ artículo I9I 5, no tendrá derecho el comprador para la rescisión de la venta, sino sólo para la rebaja del precio.

Esto me permite afirmar que el Código Civil chileno sí establece dos grados de defectos conforme a su gravedad. Para el caso en que el defecto sea grave, en el sentido ya varias veces anotado de comprometer la idoneidad del bien de forma de impedir o disminuir el uso natural o el pactado, puede ser calificado como relevante para permitir la alternativa al comprador de interponer ya sea la acción redhibitoria o la de rebaja de precio según mejor le pareciere; pero cuando el vicio no sea grave, entendiendo por tal el que no impide ni disminuye el uso del bien en forma que si el comprador lo hubiese conocido no habría celebrado el contrato o lo habría hecho a menos precio, le da exclusivamente la acción quanti minoris.

Así lo afirmó en Chile la Corte de Apelaciones de Concepción, a propósito de un caso en que la parte demandante, que había comprado un apartamento, intentó la acción redhibitoria buscando la resolución del contrato, además de la indemnización de perjuicios, alegando que el inmueble tenía un defecto grave, pues no había sido posible usar el dormitorio matrimonial ya que el tabique ubicado entre el baño y el dormitorio se había destruido. En la sentencia confirmada en apelación se estableció que el vicio alegado no era grave, pues no quedaba acreditado que por este la cosa vendida no sirviera para ser habitada. En el considerando $8 .^{\circ}$ del fallo de apelación se estableció:

... no puede concluirse que los desperfectos a que se ha hecho referencia no permitan el uso natural de la cosa vendida, estimándose que las deficiencias anotadas solo habilitan para la reducción del precio, acción que no se ha intentado ${ }^{38}$.

En la jurisprudencia de Chile y Colombia, de manera coincidente, se ha calificado también al vicio como grave en la medida en que el defecto impida o reduzca el uso de la cosa (normal o convenido), de tal forma que la gravedad se mide desde la inidoneidad o ineptitud generada en ella39. Así por ejemplo, en Colombia, en una sentencia de I968, la Corte Suprema de Justicia estableció, siguiendo para ello las palabras de la ley, que la gravedad del vicio redhibitorio se califica por el hecho de impedir o afectar el uso a que está destinado el bien ${ }^{4}$.

38 Corte de Apelaciones de Concepción, I6 de agosto de 201 I, Causa n. ${ }^{\circ} 7$ I 6/20 I I, resolución n. ${ }^{\circ}$ 39058, n. $^{\circ}$ vlex: 3 13000614.

39 De igual forma, en referencia a estos fallos, cfr. Oviedo Albán, "Sobre el concepto de vicio redhibitorio en la compraventa", cit., 244-25 I.

40 Corte Suprema de Justicia, I 5 de octubre de I968, cit. 
También en otro fallo, del 26 de marzo de 1969 , relativo a la demanda por acción redhibitoria interpuesta por una compradora de una casa que alegaba la existencia de una servidumbre de alcantarillado como vicio oculto, la Corte consideró que la gravedad del vicio redhibitorio se determina por "estorbar del todo el uso ordinario del bien enajenado o por reducirlo en forma considerable" ${ }^{\prime 1}$.

\section{B. LOS DEFECTOS QUE DESAGRADAN AL COMPRADOR}

La ineptitud o inidoneidad del bien no debe confundirse con el simple desagrado que pueda sufrir el comprador por causa de algunos defectos. En efecto, los vicios aludidos por la norma en mención deben incluir algo más que ese simple desagrado pues deben incidir en el uso del bien, disminuyendo su utilidad aunque no de manera que la impidan o reduzcan de forma considerable ${ }^{42}$.

Para esta apreciación existe respaldo jurisprudencial en el derecho chileno y colombiano. En efecto, los tribunales de Chile y Colombia coinciden en que si el vicio simplemente desagrada al comprador pero no afecta la utilidad del bien no es redhibitorio, no obstante que ello pueda dar lugar a otro tipo de acciones contra el vendedor, tal como lo hemos mencionado en trabajo anterior, en casos que conviene traer a colación nuevamente ${ }^{43}$.

En Colombia, así lo afirmó la Corte Suprema en un fallo al concluir que una servidumbre oculta por sí sola no constituye vicio redhibitorio. Los hechos que originaron el fallo fueron los siguientes: la compradora de una casa demandó a la vendedora alegando que el terreno donde se encontraba edificada comprendía una superficie mayor $y$, entre otras cosas, la existencia de un vicio redhibitorio consistente en una servidumbre de alcantarillado que limitaba con el inmueble de cuya existencia no dio la vendedora noticia alguna, en razón de lo cual pedía que se rebajara el precio y se indemnizaran los perjuicios ocasionados con la ocultación del vicio, sin el cual la compra no se hubiera realizado o se hubiera efectuado a un precio menor. La existencia de la servidumbre sólo se dio a conocer con posterioridad a la celebración del contrato, cuando a la compradora se le notificó que a la casa correspondía una cabida mayor y la vendedora estaba dispuesta a adicionársela gratuitamente, siempre que la compradora renunciara de manera expresa a toda acción por razón del vicio de la servidumbre.

En fallo de primera instancia se condenó a la vendedora por la entrega tardía del inmueble pero se denegaron las demás peticiones. En apelación, el Tribunal de la Pava, G.J., t. cxxix, núms. 2306, 2307 y 2308, 10.

Pérez Vives, ob. cit., n. ${ }^{\circ} 35 \mathrm{I}, 388$. Los vicios que simplemente desagradan al comprador pero no afectan su uso son los que alguna doctrina extranjera denomina "tolerables", en el sentido de vicios o deficiencias que resultan permisibles conforme a los usos. Orti Vallejo, ob. cit., 273. Alter, ob. cit., I32.

43 Oviedo Albán, "Sobre el concepto de vicio redhibitorio en la compraventa", cit., 252. 
Superior del Distrito Judicial de Bogotá declaró, entre otros aspectos, que la servidumbre en cuestión sí constituía vicio redhibitorio de la casa enajenada, condenando a la rebaja del precio. Contra la sentencia del Tribunal se interpuso recurso de casación por aplicación indebida de los artículos I9I4, I9I 5 y I925 c.c., a causa de error de hecho en la apreciación de las pruebas. La Corte casó la sentencia declarando el área real del inmueble objeto del contrato y denegando las demás súplicas de la demanda. Entendió la Corte que la compradora fue negligente pues de tal vicio podía darse cuenta fácilmente, "y que si no lo hizo se debió a descuido grave de su parte en examinar la cabida, las dimensiones y los servicios del inmueble comprado por ella"44. Además, enfatizó en que el vicio redhibitorio requiere, entre otros elementos: ser grave y no leve, por lo cual no constituyen vicio las imperfecciones que incomoden o desagraden al comprador o en factores extraños al uso natural de la cosa vendida o al que se destina.

Adicionalmente, en un caso de venta de un automóvil, ya citado, en que se demandó su reparación y en subsidio acción redhibitoria, afirmando que las fallas presentadas por el el vehículo constituían un vicio oculto, el tribunal de apelación consideró que el defecto alegado, que era un ruido que producía el automóvil, no constituía vicio pues no impedía o reducía la posibilidad de uso del mismo ${ }^{45}$.

De la misma forma en un fallo chileno a propósito de un caso en que el comprador demandó la rescisión de la venta de un cargamento de arroz, alegando que este presentaba vicios redhibitorios pues estaba coloreado con azul de ultramar y por ello resultaba inadecuado para el consumo. En primera y segunda instancias se consideró que este hecho no constituye vicio redhibitorio, toda vez que tal coloración no impide el uso del bien, añadiendo que al comprador correspondía probar tal factor ${ }^{4}$.

En 20ro, la Corte Suprema rechazó el recurso de casación en el fondo interpuesto contra la decisión de la Corte de Apelaciones de Santiago, que a su turno confirmó lo decidido en primera instancia por el Sexto Juzgado Civil de Santiago en el que se negaron las pretensiones del demandante, consistentes en interponer una acción redhibitoria e indemnizatoria por vicios ocultos. El vicio alegado por el demandante consistió en que el vendedor construyó un edificio frente al departamento comprado por aquel que le obstruía la vista a la cordillera, motivo por el cual había comprado el inmueble. La sentencia de apelación señaló que dicha situación no constituía vicio redhibitorio, pues no se trataba de mala calidad ni de defecto de la cosa ${ }^{47}$.

47 Corte Suprema, io de enero de 20I 2, Rol I I924, MJJ30693. 


\section{LA POSIBILIDAD DE REPARACIÓN DEL BIEN}

Cabe también analizar si el hecho de que el bien fuere o no reparable incide en la calificación de la gravedad del vicio. Las respuestas de la doctrina han sido diversas. Para algunos, la posibilidad del vicio de ser reparado no incide en su gravedad, mientras otros han afirmado que ello conduce a que el vicio no pueda ser calificado como grave. En Chile, Alessandri Rodríguez afirmó que no se requiere que el vicio sea irreparable así como tampoco se considera la duración del mismo, pues basta que tenga la gravedad exigida por la ley en el sentido ya explicado de incidir en su uso ${ }^{8}$. En Colombia, Cárdenas Mejía ha sugerido que si los defectos son reparables no son graves, por lo que sin dejar de ser vicios ocultos sólo dan lugar a la rebaja del precio49.

Este aspecto ya ha sido discutido en el derecho español, francés e italiano. En España, Badenes Gasset señala que no se requiere como requisito del defecto que este sea perpetuo o insubsanable ${ }^{50}$. En Italia, Rubino ha planteado que si el vicio es fácilmente eliminable, se excluye la resolución y por lo tanto lo que procede es la rebaja del precio $^{5}$. De igual forma, en Francia, Huet afirma que la acción redhibitoria puede ser rechazada si el vicio es fácilmente reparable, y se basa para ello en algunos casos decididos por los tribunales franceses. Así, al comentar un fallo de una corte de apelaciones que desestimó la demanda de resolución del comprador de una máquina al considerar que los vicios alegados eran de importancia pues eran susceptibles de remedio, por lo cual no se hacía impropia para su uso ${ }^{52}$. Así mismo Malaurie, Aynès y Gautier señalan en Francia que si el vicio no es de mayor importancia, versa sobre cualidades secundarias o es fácilmente reparable, no es redhibitorio porque no impide el uso de la cosa ${ }^{53}$.

En mi criterio, la reparabilidad o no del defecto sí puede incidir en la valoración objetiva que debe hacer el juez para calificar o no al vicio como redhibitorio y para decidir, por ende, si lo que procede es la redhibición o la rebaja del precio. Así, si hecha la valoración respectiva se considera que el vicio es reparable y con ello puede mantenerse el contrato, debe preferirse esta posibilidad a la rescisión del mismo, pues además resultaría como una aplicación del principio de conser-

48 Alessandri Rodríguez, ob. cit., n. ${ }^{\circ}$ I4I 3,258 , n. ${ }^{\circ}$ I 42 2, 270, n. ${ }^{\circ}$ I4 $425,276$.

49 Cárdenas Mejía, ob. cit., 229.

50 Cfr. Badenes Gasset, ob. cit., 652. En idéntico sentido: Serrano Chamorro, ob. cit., I99.

5 I Rubino, ob. cit., $778-779$.

52 Huet, Les principaux contrats spéciaux, cit., n. ${ }^{\circ}$ I I 32 I , P. 282 . El caso citado es: Com. I6 novembre 1976, non punlié au Bulletin, Gaz. Oal. I977.I. panor. 43. En el mismo sentido cita unos casos anteriores: París ro décembre 1902, Gaz. Pal. 1903-1.26r. Com. rer Juillet 1980, Gaz. Pal. I980.2. panor. 58I. Igualmente HuEt, J., Responsabilité du vendeur et garantie contre les vices cachés, Litec, Paris, I987, I84. También lo asumió así en la doctrina francesa Cottin, ob. cit., I 59.

53 Malaurie; Aynès; Gautier, ob. cit., n. ${ }^{\circ} 387,23$. En el mismo sentido Collart Dutilleul; Delebecque, ob. cit., n. ${ }^{\circ} 269,237$. 
vación, conforme al cual se debe preferir la interpretación que permita la producción de efectos del contrato a aquella que lo priva de producirlos ${ }^{54}$. En este sentido, en la doctrina italiana, Roppo ha dicho que la posibilidad de mantener el contrato de venta que se encuentra afectado por vicios ocultos mediante la reducción del precio, conforme al artículo I 492 del codice, es una de las manifestaciones de la propensión a salvar mediante adecuación el contrato, que de otra forma estaría condenado a su resolución ${ }^{55}$.

Además, considero que esta posibilidad resulta más favorable para las partes, pues puede ser benéfico para la economía del contrato y la satisfacción de sus intereses y necesidades que el vicio se repare ya sea por el propio vendedor o por el comprador, a quien en compensación se le concederá una rebaja del precio. De igual forma, si hecha la valoración del defecto se concluye que es reparable, que tal reparación puede hacerse sin ocasionar perjuicio al comprador, y que con ello la cosa sí sirve para el uso natural o pactado, el vicio dejaría de ser grave, por lo cual se verificaría el supuesto de los artículos i 868 c.c. chil. y i 925 c.c. col., y así el comprador tendría de todos modos derecho a la rebaja del precio.

En la jurisprudencia chilena existen precedentes que permiten asumir esta posición. En efecto, en un fallo antiguo de i 882, confirmado en apelación y relativo a la demanda de una compradora de unas casas que pretendía la rescisión del contrato por vicios redhibitorios originados con el desplome de las paredes, se decretó la rebaja de precio porque, aun cuando los desplomes exigían reparación, no hacían que el bien fuera inservible para el uso natural ${ }^{5}$.

Un fallo de 1932 también se refirió a los defectos de construcción como redhibitorios, pero rechazó la demanda interpuesta por el comprador de una casa quien alegó como tales la mala construcción del alcantarillado y la falta de cimientos de algunos tabiques. Se negó la demanda por considerar que tales vicios eran de poca importancia ${ }^{57}$. En un caso de 2002 , aun cuando se consideró que eran vicios los defectos originados en el diseño arquitectónico (la calidad de construcción, los defectos de ventilación y problemas en los ductos y márgenes de seguridad) que impedían la ocupación y arrendamiento de los departamentos a terceros, no se tuvieron como graves por ser reparables, además de que no im-

54 Dítz-Picazo, L., Fundamentos del Derecho Civil patrimonial. I. Introducción. Teoría del contrato, $6 .{ }^{\mathrm{a}}$ ed., Thomson Civitas, Cizur Menor, 2007, p. 498. También en el sentido de asumir que tiene incidencia en la calificación de gravedad del vicio el que sea susceptible de reparación, WAYAR, E., Evicción y vicios redhibitorios, 2, Astrea, Buenos Aires, I992, I 5 O.

55 Roppo, V., "Il contratto", en Trattato di Diritto Privato, a cura di Giovanni Iudica e Paolo Zatti, Giuffrè, Milano, 200 i, I043.

56 Corte de Santiago, 2 I de junio de i882, G. i 882, n. ${ }^{\circ}$ I 257,73 I.

57 Corte de Santiago, ig de marzo de i932, cit. 
pedían el uso normal de los bienes, pues la mayoría de ellos no eran ocultos, por lo cual se decretó la rebaja de precio $5^{8}$.

En Colombia, en una sentencia de 2005 relativa a la acción resolutoria interpuesta por el comprador de una máquina para empacar bolsas de harina, la Corte Suprema de Justicia implícitamente asumió que la reparación del bien no permite calificar el defecto alegado como falta total de entrega ni como absolutamente impropia para el uso del mismo, por lo que también la jurisprudencia colombiana asume que la reparabilidad o no de la cosa sirve como elemento para calificar o no al vicio como redhibitorio 59 . En otra parte de sus consideraciones, siendo esto discutible, la Corte señaló que la gravedad de los defectos de la cosa determina la acción correspondiente. Si el desperfecto es tal que la inutiliza totalmente, se está ante un incumplimiento del contrato atacable por la acción resolutoria general, acogiendo la teoría del aliud pro alio ${ }^{60}$. A contrario, según la interpretación de la Corte, si se trata de la calidad del objeto o su aptitud (asumiendo que la cosa sirve, pero sólo parcialmente), la acción a interponer sería la redhibitoria ${ }^{6 \mathrm{I}}$.

\section{El CARÁCTER OCULTO}

El numeral $3 .^{\circ}$ de los artículos i 858 c.c. y i 9 I 5 c.c. col. consagra como uno de los requisitos para que procedan las acciones edilicias, el carácter oculto del vicio. Así establece la norma:

$5^{8}$ Corte Suprema, I I de abril de 2002, Rol 986 - 200I, n. ${ }^{\circ}$ Legal Publishing: 24r68. Un fallo reciente decretó la rebaja de precio, pero no la resolución del contrato, al considerar que los vicios alegados, que eran fallas en la construcción de un inmueble, podían repararse: Corte de Apelaciones de Santiago, 7 de noviembre de 2012, Rol 3r 8 - 2012, n. ${ }^{\circ}$ Legal Publishing: CL/ JUR/2634/20I 2 .

59 Así dice el fallo en la parte pertinente: "En efecto, las partes aceptan, que la máquina presentó problemas de funcionamiento, pero que en últimas atañen a la eficiencia y sostenibilidad en el largo plazo, con menor necesidad de mantenimiento y cambio de piezas, defectos tales que no son de la magnitud y gravedad suficientes como para asimilarlos a una falta total de entrega, ni permiten concluir que la cosa era absolutamente impropia para desarrollar la tarea para la cual fue construida, lo que descarta la acción resolutoria general pretendida en la demanda". Corte Suprema de Justicia, Sala de Casación Civil, I4 de enero de 2005, M.P.: Edgardo Villamil Portilla, exp. 7524, en DVD - Rom, Colección furisprudencial en DVD, RSJ, Bogotá, 2009.

6o En la doctrina y jurisprudencia de algunos países, por medio del concepto de aliud pro alio o entrega de cosa distinta a la pactada se ha reconducido a una situación de incumplimiento de las prestaciones del contrato la constitutiva de vicio redhibitorio en la que por su magnitud se entienda que la cosa entregada no es la pactada. Sobre los desarrollos de esta teoría, especialmente en el derecho español, cfr., entre otros, de Elizalde Ibarbia, F., El contenido del contrato, Cizur Menor, Thomson Reuters, 20 I 5, I I6-I 44 .

6I Corte Suprema de Justicia, I4 de enero de 2005 , cit. 
No haberlos manifestado el vendedor, y ser tales que el comprador haya podido ignorarlos sin negligencia grave de su parte, o tales que el comprador no haya podido fácilmente conocerlos en razón de su profesión u oficio.

Del artículo citado se infiere que el vicio debe ser oculto al menos para el comprador. Para el vendedor, el vicio puede o no serlo, y ello no compromete la viabilidad de la acción redhibitoria ni la quanti minoris, sino la obligación de indemnizar perjuicios al comprador, tal como lo establecen los artículos I86I c.c. chil. y igr 8 c.c. col.

Del precepto normativo también se infiere que el vicio fácilmente perceptible para el comprador excluye el ejercicio de las acciones edilicias. Surgen entonces las preguntas consistentes en poder determinar: ¿cuándo el vicio es fácilmente perceptible?, ¿qué tipo de comportamiento se exige al comprador de forma que haya podido ignorarlo sin negligencia grave de su parte?, y ¿qué se exige al comprador atendiendo a los criterios subjetivos establecidos en la norma, como son la profesión u oficio?, o lo que es lo mismo: ¿qué debe hacer este para que su conducta no haga desaparecer la calificación del vicio como oculto?

Siendo éste un punto eminentemente fáctico, corresponde investigar la forma como lo han asumido los jueces y las interpretaciones que ha sugerido la doctrina.

\section{A. LA CONDUCTA EXIGIBLE AL COMPRADOR}

Entre los autores contemporáneos se acepta que para calificar el vicio como oculto o aparente deben tenerse en cuenta factores como la naturaleza de la cosa, las condiciones de venta y entrega de la misma y la competencia del comprador, de manera que la calificación dependerá de si este aparece en una verificación inmediata y mediante una investigación "normal” que podría hacer cualquier persona que se encontrare en las mismas condiciones del comprador, es decir, mediante una apreciación en abstracto ${ }^{62}$. Ahora, si el comprador fuere un profesional o una persona con experiencia técnica, dada su actividad, para poder detectar más fácilmente la presencia del vicio, la valoración deberá hacerse en concreto, por lo cual se le exigirá algo más que simplemente observar el bien, debiendo realizar un examen del mismo de acuerdo con su grado de experticia ${ }^{6}{ }^{2}$.

La jurisprudencia de Colombia y Chile ha asumido que el grado de conocimiento o negligencia y aspectos particulares como su experiencia, actividad etc., tienen relevancia para la calificación de ocultos dada a los vicios. En Colombia se

62 Huet, Responsabilité du vendeur, cit., I96. Huet, Les principaux contrats spéciaux, cit., n. ${ }^{\circ}$ I I $296,262$. Ghestin, ob. cit., n. ${ }^{\circ}$ I 5, 22-23. Le Tourneau, Ph., Responsabilité des vendeurs et fabricants, $4 .{ }^{\text {e éd., }}$ Dalloz, Paris, 201 I, 278. Aguayo, ob. cit., 375. Morales Moreno, "Artículo I484", cit., 957.

63 Ghestin, ob. cit., n. ${ }^{\circ}$ I 5, 23. Aguayo, ob. cit., 376. 
ha sentado un criterio consistente en afirmar que constituye vicio redhibitorio el oculto a simple vista, es decir: el que el comprador no puede conocer porque no puede ser percibido con una simple observación del bien. Igualmente, cuando el vendedor no lo conoció o, conociéndolo, no lo declaró.

Del artículo surge aquel concepto de la "simple observación del bien" para detectar la presencia o no de vicios redhibitorios que resulta correcto, pues de la norma se deduce que al comprador no se le exige una revisión rigurosa del bien para detectar el vicio; en efecto, según lo establecido en ella, este debe ser tal que el comprador pueda desconocerlo sin incurrir en culpa grave, y según lo que se infiere de los artículos 44 c.c. chil. y 63 c.c. col., este tipo de culpa es la que impone un cuidado menor al comportamiento de una persona ${ }^{64}$.

En un fallo de I899, la Corte Suprema de Justicia de Colombia asumió que para establecer si los vicios son ocultos basta determinar si son evidentes o no al sentido de la vista. Entre las partes se celebró un contrato de compraventa de una hacienda. El comprador demandó pidiendo como pretensión principal la rescisión del contrato, la restitución del precio y la correspondiente indemnización de perjuicios por no haber cumplido el vendedor sus obligaciones al haber pretendido obligar al demandante a recibir el bien sin todo lo que se vendió aunque exigiendo todo el precio. En subsidio pidió que se declarase resuelto el contrato con la correspondiente indemnización. El demandante alegó que en la hacienda había muchos menos bienes (árboles, cafetales, etc.) que los indicados en el contrato y algunos en mal estado (como animales, etc.). El juzgado de primera instancia decretó la rescisión del contrato, la restitución del precio y los perjuicios. En apelación, el Tribunal Superior del Distrito Judicial de Cundinamarca confirmó la sentencia de primera instancia pero la modificó en lo referente a la indemnización.

Las partes demandante y demandada interpusieron recurso de casación contra el fallo del Tribunal por aplicación indebida e interpretación errónea de las normas respectivas. La Corte Suprema casó la sentencia aduciendo que no era procedente la acción de rescisión y decretó la resolución del contrato, absolviendo al demandado de los perjuicios solicitados por no haberse probado dolo. Además de distinguir el saneamiento por vicios ocultos del incumplimiento del contrato por faltar una parte considerable del bien según lo establecido en el artículo I 870 c.c., señaló que el mal estado del inmueble no constituía vicio oculto pues el comprador habría podido advertirlo con mediana diligencia al momento de celebración del contrato, para lo cual simplemente se requiere utilizar el sentido de la vista ${ }^{6}$.

64 Abeliuk Manasevich, R., Las obligaciones, t. II, 6. ${ }^{\text {a }}$ ed., Santiago, Thomson Reuters-La Ley, $2014,963$.

65 Corte Suprema de Justicia, 5 de julio de I899, G.J., xIv, núms. 7 I 3 y 7 I 4, 282. 
Así también en otro caso, a propósito de una demanda interpuesta por el comprador de un inmueble para que se rebajara el precio por vicios redhibitorios. El juez de primera instancia negó las pretensiones, señalando que el demandante interpuso su acción basándose en el dicho de testigos, y que tratándose de vicios redhibitorios deben establecerse con el dictamen de expertos. En apelación, el Tribunal Superior del Distrito Judicial de Medellín revocó la sentencia de primera instancia y en su lugar decretó la rebaja del precio y el pago de los perjuicios sufridos por el comprador. El Tribunal se basó en una prueba pericial de inspección ocular practicada en segunda instancia. La Corte Suprema en casación confirmó la sentencia y en sus argumentos señaló que los vicios ocultos no son observables por personas inexpertas, por lo cual se requiere prueba pericial $^{66}$.

En sentencia de 2007 , la Corte Suprema insistió en que no será oculto el vicio denunciado por el vendedor ni el que ha podido ser conocido fácilmente por el comprador sin mayor esfuerzo de su parte:

... cuestión ésta que el juzgador debe examinar apreciando objetivamente el comportamiento de dicha parte contratante, en aras de definir si su ignorancia del vicio puede estimarse libre de culpa grave y, por tanto, si el defecto debe o no reputarse oculto ${ }^{67}$.

Los tribunales chilenos también han establecido el criterio conforme al cual si el vicio no es perceptible a la vista es oculto y, como tal, redhibitorio. Así en un caso fallado por la Corte de Santiago en i 884, relativo a un contrato de compraventa de un caballo que al momento de celebración del contrato sólo presentaba una peladura que resultó ser una enfermedad llamada galápagos. El comprador demandó la rescisión del contrato alegando que se trataba de un vicio redhibitorio. La Corte de Santiago consideró que se trataba de un vicio oculto pues a simple vista el defecto era una simpe rasmilladura ${ }^{68}$.

Por el contrario, cuando el comprador fuere un experto se requiere que el comprador haga algo más que mirar el bien. Los tribunales han analizado este caso en el sentido de que si el comprador es un profesional de la respectiva actividad o conocedor del bien en cuestión, se exige un grado de diligencia mayor.

66 Corte Suprema de Justicia, Sala de Casación Civil, 6 de marzo de 1945, M.P.: Fulgencio Lequerica Vélez, G.J., LVIII, 638 .

67 Corte Suprema de Justicia, Sala de Casación Civil, M.P.: Pedro Octavio Munar Cadena, 6 de agosto de 2007, exp. I300I 3I 03 OOI I 999 O0I 57 OI, en Notinet. En este caso el comprador interpuso la acción estimatoria buscando la rebaja del precio en un contrato de compraventa de un terreno al considerar que existía un vicio redhibitorio consistente en que una parte del predio estaba rellenada con material vegetal inconsistente sobre el cual no podía adelantarse ninguna construcción.

68 Corte de Santiago, I9 de agosto de I884, G. I884, n. ${ }^{\circ} 2030$, I 244. 
Así, en efecto, se ha requerido en este tipo de casos mayor prudencia del comprador, para no incurrir en negligencia grave de su parte ${ }^{69}$.

También en la jurisprudencia se ha señalado que para determinar el carácter oculto del vicio deben tenerse en cuenta aspectos concretos del comprador, tales como su grado de educación, experticia e incluso el "sentido común”. Así, en un caso, ya citado, en que el comprador de un departamento demandó acción redhibitoria e indemnización de perjuicios, alegando como vicio la construcción de un edificio que le impedía la vista a la cordillera, se afirmó que la situación específica alegada como vicio "supone ciertos antecedentes de lógica, sentido común e información o conocimiento del comprador", además de tener en cuenta para ello el "nivel educacional de la demandante [...] y el monto de la transacción"7o.

\section{B. El DEBATE ACERCA DE LA INTERVENCIÓN DE PERITOS}

No obstante que la posición adoptada en el derecho chileno y colombiano ha sido la de no exigir al comprador nada diferente a mirar el bien para verificar la presencia o no de vicios redhibitorios, de todas maneras el tema en la doctrina y en la jurisprudencia de ambos países no ha sido uniforme y pacífico, como paso a considerarlo. Así, mientras para algunos basta un examen simple del bien, de modo que si a simple vista el vicio no se manifiesta es oculto, para otros se requiere la asesoría de expertos atendidas las circunstancias del comprador.

En Chile, Alessandri Rodríguez consideró en su momento que el comprador no comete negligencia grave por no realizar un examen minucioso sobre el bien, bastando con que la examine "más o menos atentamente", por lo que si el vicio no se ve a simple vista y su descubrimiento requiriere un examen muy detenido o que presentare dificultades, se reputaría oculto ${ }^{71}$. También afirmó el autor que la falta de experiencia o conocimientos del comprador para apreciar si la cosa presenta o no vicios, de forma que no los descubre a pesar del cuidado puesto en examinarla, tampoco constituye negligencia grave ${ }^{72}$. Sostuvo que si el comprador es un profesional tendría derecho al saneamiento si el vicio solo pudo observarse con un examen "más o menos complicado que no es costumbre hacer"73.

En Colombia, los autores no han dado mayores explicaciones, limitándose a comentarios breves donde parafrasean el texto normativo. Así VéLEz, quien señaló en su momento que si el vendedor no manifiesta el vicio, el comprador no puede ignorarlo sin negligencia grave, y enfatizó que en cada caso concreto el

69 Corte de Santiago, 25 de julio de г88 I, G. г 88 I, n. ${ }^{\circ}$ г $278,762$.

70 Corte Suprema, io de enero de 20 I 2, Rol I I924, MJJ30693.

7 I Alessandri Rodríguez, ob. cit., n. ${ }^{\circ}$ I 432 , 284.

72 Ibíd, p. 285.

73 Alessandri Rodríguez, ob. cit., n. ${ }^{\circ}$ I $433,288$. 
juez deberá valorar según la naturaleza de los vicios o calificar los conocimientos del comprador, para resolver si en razón de su profesión u oficio pudo fácilmente conocerlos 74 .

Según Pérez Vives se deben analizar los distintos factores que pueden incidir en la calificación como oculto del vicio preguntándose si la ley atiende al mayor o menor ocultamiento del bien o a la buena fe, entendida como ignorancia excusable del comprador para determinar cuándo hay o no vicio oculto, de manera que el numeral $3 .^{\circ}$ del artículo i9r 5 c.c. col. (i 858 c.c. chil.) puede entenderse en el sentido de que el vicio es oculto en tres supuestos: a) cuando el comprador haya podido ignorarlo después de haber hecho lo que en semejantes casos haría un hombre poco prudente y no diligente; b) cuando por razón de su profesión dicho comprador no estuviera obligado a conocerlo, y c) cuando el vendedor no lo puso en conocimiento de aquel, de forma que hay vicio cuando haya ignorancia excusable por parte del comprador ${ }^{75}$.

El autor manifestó su discrepancia con Alessandri Rodríguez en el punto en que este afirma que si el comprador no es un experto no debe asesorarse de un profesional para observar el bien, y calificó como de "elemental prudencia" que el comprador que va a adquirir una cosa y está en imposibilidad de saber si esta es de buena o mala calidad se asesore de un especialista, de manera que la falta de dicha precaución constituiría negligencia, descuido o culpa grave ${ }^{76}$.

Otros sectores de la doctrina colombiana han sostenido una posición diferente a la de Pérez Vives, como por ejemplo Rodríguez Fonnegra, al afirmar que la negligencia a que se refiere la norma consiste en "la no aplicación de los sentidos con atención ligera" y no en omitirse el asesoramiento de técnicos 77. Para Valencia ZEa, no es redhibitorio el vicio aparente ni el que con mediana diligencia habría podido conocer el comprador, aunque sin establecer qué significa exigirle a este un "mediano cuidado"78. Por su parte, Gómez Estrada, con base en sentencia de la Corte Suprema de Justicia del I 5 de octubre de i968, ya citada, afirmó que el no asesorarse de expertos es una culpa leve sin fuerza para privar al comprador de la acción redhibitoria79.

En época más reciente, Tamayo Lombana se expresa en contra de lo sostenido por Pérez Vives, al afirmar que la norma invita a una apreciación in abstracto, por lo que el juez deberá preguntarse si alguien con los mismos conocimientos

74 “... porque si hubiera examinado la cosa con el cuidado que aun las personas negligentes o de poca prudencia suelen emplear en sus negocios (art. 6), lo habría notado, o tal que el comprador en razón de su profesión u oficio, lo hubiera podido fácilmente conocer": VéLEz, ob. cit., 250.

Pérez Vives, ob. cit., n. ${ }^{\circ}$ 335, 37 I a 374.

76 Ibíd.

77 Rodríguez Fonnegra, J., De la compraventa y materias aledañas, Bogotá, Lerner, i 960, 874-875.

78 Valencia Zea, ob. cit., 90.

79 Gómez Estrada, ob. cit., 94. 
que el comprador habría descubierto el vicio, en cuyo caso, si se respondiere negativamente, no podría calificarse como negligente al comprador ${ }^{80}$. BonIVENTo se aparta igualmente de la tesis de Pérez Vives al afirmar que el comprador inexperto no tiene que buscar otros medios superiores a sus propios conocimientos para descubrir las condiciones internas de la cosa, pues eso significaría, según el autor, que solamente en aquellos casos en que el vicio se puede esconder aun a los técnicos es susceptible de ser redhibitorio, asumiendo que el vicio debe ser oculto a simple vista ${ }^{8 \mathrm{I}}$.

En la doctrina francesa clásica algunos autores sostuvieron en su momento la necesidad de la intervención de peritos en los casos en que el comprador fuere inexperto. Así BAudry-Lacantinerie y Saignat, quienes afirmaron que la inhabilidad e inexperiencia del comprador no permite considerar como oculto un defecto cuando este aparece a una persona más competente, que tiene los conocimientos necesarios para apreciar la cosa. De esta manera, por ejemplo, quien compra una casa debería acudir al consejo de un arquitecto para que la revise, pues no podrá después alegar su ignorancia para efectos de pedir la rescisión del contrato por causa de los vicios ${ }^{82}$. También Spota, en Argentina, al señalar que si el comprador carecía de los conocimientos inherentes a una determinada profesión u oficio, debe imputarse a su propia negligencia el hecho de carecer de buena fe diligente al no haber requerido el auxilio de un técnico ${ }^{8}$.

En Chile se adoptó esta posición en fallo de la Corte de Santiago de i 884, ya referido, relativo a la enfermedad de un caballo que fue alegada como vicio redhibitorio. Ante la demanda de rescisión del comprador, la Corte consideró

80 Tamayo Lombana, A., El contrato de compraventa, su régimen civil y comercial, Bogotá, Ediciones Doctrina y Ley Ltda., 2004, I80-18 I.

8 i Bonivento Fernández, J.A., Los principales contratos civiles y su paralelo con los comerciales, i 7 . $^{\mathrm{a}} \mathrm{ed}$., Bogotá, Librería Ediciones del Profesional, 2008, I45.

82 Baudry-Lacantinerie y Saignat, ob. cit., n. ${ }^{\circ}$ 4i 8, 426. Igualmente Planiol y Ripert, quienes afirmaron que "el comprador que conozca su impericia debe acudir a aquellas personas competentes y habrá incurrido en culpa por haber confiado demasiado en su capacidad". Planiol, M. y Ripert, G., Tratado práctico de Derecho Civil francés, t. vi, Las obligaciones, primera parte, Díaz Cruz, Mario (trad.), con la colaboración de Eduardo Le Riverend Brusone, La Habana, Cultural, I946, I33.

83 Spota, A. G., Instituciones de Derecho Civil. Contratos, v. Ix, Buenos Aires, Depalma, I984, n. ${ }^{\circ}$ I885, 60. En la doctrina argentina asume una posición intermedia BoRDA, pues aunque en principio niega que al comprador deba exigírsele estar asesorado por un experto, afirma que la complejidad de la cosa comprada o su valor económico pueden ser factores a considerar para exigir que el comprador si fuere inexperto esté asesorado por especialistas. Borda, G., Tratado de Derecho Civil, Contratos, t. I, 8. ${ }^{a}$ ed. actualizada con la colaboración de Alejandro Borda, Buenos Aires, Lexis Nexis-Abeledo Perrot, 2005, n. ${ }^{\circ} 222$, I6I-I62. Similar la posición de Mrquel, S., "Responsabilidad por vicios redhibitorios en los contratos civiles, comerciales y de consumo", en Derecho de los contratos. Técnica de la contratación actual. Libro en homenaje a la escribana Beatriz A. Maury, Buenos Aires, Ad-Hoc, 2008, 178. 
que este no había incurrido en negligencia grave al no hacer examinar el bien, pues a simple vista se trataba de una mera rasmilladura ${ }^{8}$.

En la jurisprudencia colombiana la calificación como experto o inexperto del comprador es un tema que ha sido debatido, habiéndose generado dos interpretaciones diferentes. La posición actual es la de no requerir al comprador profano asesorarse de expertos. No obstante, en I955 la Corte Suprema de Justicia se separó de la interpretación tradicional en un caso de una acción redhibitoria interpuesta por el comprador de un vehículo, a partir de la cual asumió que si el comprador no es un experto, debería asesorarse por peritos, pues de lo contrario incurriría en negligencia grave.

El caso discutido versó sobre la compra de un automóvil y la demanda interpuesta por el comprador para que se rescindiera el contrato por la existencia de un vicio oculto, consistente en fallas en sus piezas, por lo cual no podía destinarse al intercambio comercial y no podía ser conocido por aquel al momento de su celebración. En las diferentes instancias se negó la pretensión del comprador, no solamente porque no se pudo probar la existencia del vicio al tiempo del contrato, sino además porque se entendió que el defecto no era oculto, pues si el comprador era inexperto debía hacer examinar el bien de una persona que sí lo fuera. En este caso la Corte Suprema estableció que tanto el vendedor como el comprador tienen el deber de examinar el bien para saber si está en buenas condiciones y puede ser objeto del contrato. La interpretación asumida por la Corte consistió en establecer que el vicio no tiene la calidad de oculto cuando, si bien no es perceptible por el comprador inexperto, surge inmediatamente para uno más competente, de manera que el comprador inexperto tiene el deber de acudir a peritos, o de lo contrario incurriría en culpa ${ }^{85}$.

Esta interpretación cambió cuando la Corte Suprema, en decisión de I968, asumió que el comprador inexperto no está en la obligación de hacer examinar el bien por un perito. El caso fue el siguiente: se celebró un contrato de compraventa de una casa que estaba en aparentes buenas condiciones al momento de perfección del mismo. Posteriormente, algunas de sus paredes empezaron a agrietarse y se presentó deformación de puertas y ventanas y hundimiento de pisos. La compradora demandó alegando la existencia de un vicio redhibitorio y pidió que se condenara al vendedor a la rebaja del precio e indemnización por los daños originados por los vicios. La sentencia de primera instancia absolvió al demandado, y recurrida en apelación el Tribunal Superior de Distrito Judicial de Bogotá la confirmó, teniendo en cuenta el acervo probatorio que demostró que los daños no se originaron en vicios ocultos sino en motivos ajenos al vendedor

84 Corte de Santiago, i9 de agosto de i884, cit.

85 Corte Suprema de Justicia, Sala de Casación Civil, 23 de junio de 1955, M.P.: Agustín Ariza Prada, G.J., t. Lxxx, n. ${ }^{\circ} 2$ I 53, $45^{2}$. 
demandado, como fue la deficiente construcción de un edificio contiguo. Esta sentencia fue confirmada en casación ${ }^{86}$.

La Corte Suprema consideró igualmente que el criterio de valoración de los defectos ocultos es "objetivo-subjetivo",

... en el sentido de que la valoración ha de partir de la verificación de la existencia del vicio y el daño, de su importancia y de la época en que se haya presentado y gestado, para pasar luego a averiguar la conducta observada por el adquirente a fin de determinar si éste es o no acreedor de la protección que le brindan las acciones redhibitoria y estimatoria, respecto de las cuales el proceder del enajenante es indiferente [...] pues éste sólo es relevante para determinar si como complemento, procede también la indemnización de perjuicios ${ }^{87}$.

Según la Corte, el numeral $3 .^{\circ}$ del artículo i9 5 c.c. introduce un elemento subjetivo, "que consiste en averiguar el conocimiento que el adquirente tuviera o no del vicio y, en caso negativo, si la ignorancia del mismo obedeció o no a grave negligencia de su parte”. Destacó además que esta característica es la que ha generado mayores problemas a nivel doctrinal y jurisprudencial. Citando la sentencia de casación del 5 de julio de 1899 ya referida, recordó que en aquella oportunidad la Corte señaló que los vicios tienen el carácter de ocultos cuando aplicando el sentido de la vista no se puedan descubrir dichos defectos. Criticó la Corte esta sentencia al considerar que se requiere algo más que "mirar para ver", pues la norma señala que debe tenerse en cuenta la profesión u oficio del comprador para determinar si los vicios son ocultos. Igualmente destacó un segundo concepto como contradictorio con el anterior, pues le exige al comprador proceder con mediana diligencia y cuidado, "o sea prestar la culpa leve, al paso que el citado texto legal sólo exige actuar sin negligencia grave", indicando que este fue reiterado por la Corte en fallo del 23 de junio de 1955 , en el cual se censuró a un comprador inexperto por haber incurrido en negligencia al no haberse asesorado de un perito que dictaminase sobre el estado de un vehículo a la celebración del contrato. Consideró la Corte que la sentencia de 1955 incurrió en un error al haberse apoyado en el pensamiento de autores franceses, sin tener en cuenta "diferencias fundamentales que se ofrecen entre el sistema a que ellos se refieren y el colombiano en punto de la valoración de la culpa”, indicando cómo el Código francés no adoptó la teoría de la tripartición de las culpas, sino un sistema de culpa única, la leve,

... que se hace consistir en la falta de aquella diligencia y cuidado que un varón prudente emplea ordinariamente en los negocios. Por tanto, resulta consecuente

86 Corte Suprema de Justicia, I5 de octubre de 1968, cit.

87 Ibíd. 
con el mencionado sistema la tesis que imputa responsabilidad al comprador de cosa viciosa cuando no haya tratado de descubrir los defectos con esa prudencia y cuidado medianos que a todos les son exigidos por igual ${ }^{88}$.

Destacó que el Código Civil colombiano, por el contrario, sí acogió la teoría de la prestación de las culpas en el artículo 63:

... en punto de la institución de los vicios ocultos, el Código también introduce importante aplicación de la teoría de la prestación de las culpas al determinar que el comprador solamente asume el riesgo de tales vicios, cuando no ha podido ignorarlos "sin negligencia grave"

O sea, según la definición del artículo 63, sin "aquel cuidado que aún las personas negligentes o de poca prudencia suelen emplear en sus propios negocios”. Así entonces, afirmó la Corte en el fallo que lo oculto o no del vicio redhibitorio para el comprador es una cuestión de hecho que el juzgador ha de apreciar directamente, pero siempre dentro de las pautas expresamente señaladas por la ley: la facilidad con que aquel pudiera conocer los vicios en razón de su profesión u oficio y el haber incurrido o no, en la averiguación de los mismos, en una negligencia tal que sea injustificable aun en las personas imprudentes y descuidadas; y precisó además:

De esta suerte la asunción del riesgo de los vicios por el adquirente de una cosa queda reducida a casos verdaderamente excepcionales, lo que es justo y, además se acomoda mejor a la ya aludida tendencia doctrinal moderna que, atendiendo al creciente tráfico de los productos de mediana y larga duración, propugna el establecimiento de una garantía puramente objetiva en favor de los adquirentes de cosas viciosas ${ }^{90}$.

La Corte Suprema confirmó la sentencia del Tribunal, por asumir que los vicios ocultos no existieron al momento de la celebración del contrato y los daños no obedecieron a defectos de construcción ${ }^{91}$.

Esta interpretación es acorde con la establecida por la jurisprudencia en otros fallos, consistente en señalar que el carácter oculto de un vicio radica en que el mismo no es perceptible a los sentidos, sin requerir un examen cuidadoso 
del bien, o lo que es lo mismo: que el vicio no haya podido ser conocido o descubierto fácilmente y sin esfuerzo por el comprador ${ }^{2}$.

\section{Consideraciones}

La interpretación hecha por los tribunales chilenos resulta conforme con lo que sobre el particular ha sostenido la doctrina contemporánea. De esta forma, entre los autores españoles, Verda y BeAmonte, apoyado en fallos de su país que así lo han decidido, afirma que si el comprador fuere profano, esto es, no un experto en relación con el bien según su profesión u oficio, sólo se le exige una mínima diligencia que permita determinar si la cosa está o no exenta de vicios ${ }^{93}$. En Italia, Rubino también ha expresado que en la inspección del bien el comprador no debe tener la diligencia media del buen padre de familia, sino solo una diligencia mínima, lo cual significa que pierde el derecho a la garantía cuando incurre en culpa grave; y que además la expresión "fácilmente reconocible" no puede significar sino que la ley se contenta con una menor diligencia de parte del comprador. De otra parte, el comprador no tiene el deber de hacer examinar el bien por un técnico para quien el vicio podría ser fácilmente reconocible, pues esta mayor cautela no entra en el grado de diligencia exigido 94.

En la doctrina francesa reciente, con base en fallos que así lo han aceptado, los autores indican que si el comprador es un profano, el vicio es oculto para él cuando con un simple examen este no aparece, sin que se le deba exigir estar asistido de un experto, o lo que es lo mismo: el vicio tiene carácter oculto cuando para descubrirlo se necesita la revisión de un perito95. Según Huet, si bien es cierto algunas decisiones judiciales exigieron en su momento que la persona inexperta se valga de un técnico para descubrir el vicio, la Corte de Casación no se ha pronunciado en tal sentido, exigencia calificada por el autor como injustificada para con el comprador ${ }^{6}$.

92 Corte Suprema de Justicia, 25 de marzo de i969, cit. En fallo posterior, a propósito de un caso en el que se alegaban como vicios redhibitorios los defectos que presentaban los componentes de una camioneta, la Corte ha insistido en esta posición al señalar que no puede exigirse al comprador estar asesorado siempre de un experto. Corte Suprema de Justicia, Sala de Casación Civil, I I de octubre de I977, M.P.: Germán Giraldo Zuluaga, (no publicada).

93 Verda y Beamonte, ob. cit., 93. En igual sentido Eugenio Llamas Рombo, La compraventa, Madrid, La Ley, 20 4, 509.

94 Rubino, ob. cit., 783.

95 Bénabent, ob. cit., n. ${ }^{\circ}$ 362, i 62 - i63. Collart Dutilleul; Delebecque, ob. cit., n. ${ }^{\circ}$ 276, 242 . Le Tourneau, Ph., "Conformités et garanties dans la vente d'objets mobiliers corporels", en RTD Com., t. xxxiII, (I 980), 245. Le Tourneau, Ph., Droit de la responsabilité et des contrats, neuvième éd., Dalloz, Paris, 20 I 2, i 575. Malaurie; Aynès; Gautier, ob. cit., n. ${ }^{\circ}$ 39 I, 232.

96 Huet, Responsabilité du vendeur, cit., 200. Huet, Les principaux contrats spéciaux, cit., n. ${ }^{\circ}$ I 329 , 288. 
En España, Aguayo ha dicho recientemente que no puede concluirse en todos los casos que no sea necesaria le presencia de expertos, y plantea como argumento para exigirla la complejidad y envergadura de la operación, lo cual según el autor puede hacer conveniente y necesaria la intervención de expertos. El ejemplo utilizado por el autor es el del una empresa multinacional de un país no occidental que adquiera una empresa, también multinacional, en España, caso en el cual, plantea, es difícil pensar que no se valga de asesores expertos para realizar la operación 97 .

Frente a esta aparente objeción, considero que el autor en realidad no se separa del criterio mayoritario como pretende, puesto que, antes al contrario, el ejemplo propuesto en el que comprador es una empresa "profesional" de cierta actividad lleva a que la diligencia exija valerse de asesores expertos.

En efecto, en el derecho chileno y colombiano, si el comprador es un experto o profesional en relación con la cosa y el tipo de vicio que lo aqueja, sí se requiere una diligencia mayor que mirar el bien. La norma así lo establece cuando dispone que los vicios deben ser tales que “... el comprador no haya podido fácilmente conocerlos en razón de su profesión u oficio”. En la doctrina se señala que si estos vicios entran dentro de la competencia técnica del comprador es más dificil considerarlos ocultos, pues él es capaz de una verificación minuciosa para descubrirlos, por lo cual habría una especie de presunción de conocimiento de los vicios, de manera que su ignorancia sería inexcusable $e^{8}$.

Así se decidió en un fallo antiguo conocido en apelación por la Corte de Santiago. El comprador de una cantidad de harina demandó al vendedor pretendiendo la restitución de las prestaciones e indemnización de perjucios alegando que esta no era de primera clase sino inservible, por lo que debió comprar pan a otros panaderos para poder cumplir con algunos contratos. El fallo confirmado en apelación, por el cual se absolvió al demandado, analizó el caso del comprador experto y consideró que dada su experticia no era verosímil que no conociera la calidad de la harina ofrecida, o que, no conociéndola, no la hubiera puesto a prueba o no se hubiera detenido después del primer ensayo que le dio malos resultados 99 .

De esta forma se puede asumir que si el adquierente es un profesional de la respectiva actividad o conocedor del bien en cuestión, se le exige un grado de diligencia que supera el simplemente mirar el bien para detectar la presencia del vicio, y de esta forma se requiere mayor prudencia del comprador para que no incurra en negligencia grave de su parte.

97 Aguayo, ob. cit., 379 .

98 Huet, Responsabilité du vendeur, cit., 200. Huet, Les principaux contrats spéciaux, cit., n. ${ }^{\circ}$ I 330 , 289. le Tourneau, Responsabilité des vendeurs et fabricants, cit., 279. Le Tourneau, Droit de la Responsabilité et des contrats..., cit., I 575. Malaurie; Aynès; Gautier, ob. cit., n. ${ }^{\circ}$ 392, 232.

99 Corte de Santiago, 25 de julio de i88 I, cit. 
En el Código de Comercio colombiano, el artículo 934 establece que los vicios deberán haber sido ignorados "sin culpa" por el comprador, sin que esta sea calificada. Esto conlleva, aplicando lo dispuesto en el artículo 63 c.c. col., que al comprador en materia mercantil se le exija una mayor diligencia al observar el bien, pues de lo contrario incurriría en culpa leve ${ }^{100}$. Así entonces, a diferencia de lo que sucede en materia civil, el comprador mercantil deberá hacer algo más que simplemente "mirar" el bien para verificar que esté libre de defectos, como podría ser revisarlo, inspeccionarlo con mayor cuidado o realizar una prueba del mismo. En la doctrina colombiana no hay mayores comentarios sobre el alcance de este artículo. Rengifo, al referirse a esta norma, señala también que cuando se trata de una venta entre comerciantes, se supone que el comprador es un experto conocedor y por tanto está en capacidad de examinar detalladamente el bien para detectar defectos que otro no podría advertiriroI. Por su parte, CárDenas Mejía, al comentar el mismo artículo, afirma además que en todo caso el Código de Comercio adopta un criterio más exigente aun para el comprador no profesional ${ }^{102}$.

En mi parecer, ello resulta justificado en la medida en que al referirse a compraventas mercantiles puede asumirse que se trata de un comprador profesional, que por su calidad de comerciante está en capacidad de conocer mejor el bien objeto del contrato, lo cual haría que la diferencia con la regla civil sea aparen$\mathrm{te}^{\mathrm{IO} 3}$. Además, tratándose de compradores no profesionales, como es el caso de los consumidores, cabe recordar que el artículo 23 n. ${ }^{\circ}$ i c.co. col. excluye de su campo de aplicación, al calificarlas como no mercantiles, a la adquisición de bienes con destino al consumo doméstico o al uso del adquirente, y a la enajenación de los mismos o de los sobrantes, de forma que a ellas se aplicará el Código Civil, sin perjuicio de las reglas especiales sobre garantías conforme al Estatuto del Consumidor. Si se trata de una persona que no es experta y realiza compras que no están excluidas del ámbito de aplicación del código de comercio, la norma resulta más exigente al requerir un mayor cuidado para detectar el vicio, lo que tal vez resulta justificado por el tipo de operaciones a realizar. Por esto considero correcta la posición de RENGIFo, quien sobre el particular señala que el comprador deberá asesorarse de un experto pues de lo contrario incurriría en culpa ${ }^{104}$.

ioo Cárdenas Mejía, ob. cit., 23 I.

io I Rengifo, R., Contratos comerciales, v. I, La compraventa mercantil, el transporte, el suministro, 2. ${ }^{\text {a }}$ ed., Colección Pequeño Foro, Medellín, I98 I, 47.

IO2 Además, señala el autor, "el Código de Comercio no establece diferencia entre el profesional y el no profesional, pues simplemente señala que el vicio no debe ser ignorado sin culpa. Esta regla implica la comparación de la conducta del comprador con un modelo abstracto, que estaría constituido por una persona medianamente prudente y diligente". CÁrdenas Mejí́, ob. cit., 23 I .

IO3 Rengifo, ob. cit., 47 .

I04 Ibíd. 
Aunque ya lo he sugerido en los párrafos anteriores, me parece necesario resaltar mi acuerdo con la interpretación según la cual, conforme a las reglas civiles, no se requiere que el comprador esté asesorado de expertos para examinar el bien y determinar la ausencia de vicios en el mismo. Exigirle tal conducta sería obligarlo a una diligencia máxima cuya inobservancia generaría culpa levísima. Por el contrario, el tenor literal comentado señala que los vicios deben ser ocultos, de tal forma que el comprador no incurra en negligencia grave de su parte, es decir: que no haya culpa grave, lo cual se opone a un comportamiento excesivamente cuidadoso. Esta es la interpretación con sustento en la jurisprudencia, en la cual a su vez se ha asumido que el vicio es oculto cuando no puede ser percibido con una simple observación del bien, y que el comprador no incurre en negligencia grave cuando no se asesora de expertos para examinarlo ${ }^{105}$. Además, el asesorarse de expertos para la revisión del bien es una exigencia en contra de la agilidad requerida por el tráfico moderno, pero además significaría obligar al comprador a incurrir en costos adicionales para la adquisición de bienes, al tener que contratar expertos que examinen el bien en cada uno de los contratos celebrados a diario.

\section{La prueba del vicio redhibitorio y sus requisitos}

Cabe preguntarse a quién corresponde probar el vicio redhibitorio y sus requisitos. Un sector doctrinal ha señalado que es el comprador quien tiene la carga de la prueba. Así, apoyándose en los artículos i 698 c.c. chil. y I 757 c.c. col., a cuyo tenor debe probar las obligaciones o su extinción el que alega aquellas o esta, Alessandri Rodríguez sostuvo que corresponde al comprador probar la existencia del vicio al tiempo del contrato, así como el carácter oculto del mismo, demostrando que ignoró la existencia del vicio, y por tanto su gravedad, porque el vendedor no se lo manifestó, y que no lo pudo conocer a pesar de haber examinado la cosa ${ }^{\text {106 }}$.

io5 Alessandri Rodríguez, ob. cit., n. ${ }^{\circ}$ I432, 284. En este sentido, en la doctrina argentina, Wayar, en posición que compartimos, señala que no se trata de privilegiar al comprador negligente y descuidado, de forma que se requiere solamente un examen atento del comprador, sin necesitar la ayuda de expertos, como por ejemplo, dice, al comprar un inmueble, caso en el que es suficiente una revisión ocular. WAYAR, ob. cit., I40-142.

io6 Alessandri Rodríguez, ob. cit., n. ${ }^{\circ}$ I 4 I 8 y n. ${ }^{\circ}$ I 438, 265 y 290. El autor manifestó que el juez podría, en caso de que no se pudiera acreditar por el comprador de forma directa la preexistencia del defecto, inferirlo por medio de presunciones. Aunque sin mayores argumentos, en Chile la Corte Suprema ha señalado que es al comprador a quien corresponde probar la existencia del vicio. Cfr. Considerando cuarto, Corte Suprema, i 8 de enero de 20 I I, cit. En idéntico sentido, en la doctrina española, Orti Vallejo, ob. cit., 282. También, como lo afirma Verda y BeamonTE, apoyándose para ello en fallos de tribunales españoles, esta prueba podría basarse en presunciones, aunque estas no proceden cuando de los hechos pueda inferirse que la conclusión es otra, como en el caso de la mala utilización del bien por el comprador. Cfr. Verda y Beamonte, ob. cit., I 28 -I 3 I. 
Esta es la posición seguida por la mayoría de los autores colombianos en diferentes épocas, al señalar que es al comprador a quien corresponde probar la gravedad del defecto y la existencia de este al momento de celebración del contrato ${ }^{107}$. No obstante, Pérez Vives ha propuesto diferenciar dos momentos: según el primero, si los vicios aparecen antes de la entrega, le asigna la carga de la prueba al vendedor, por considerar que es a este a quien le corresponde cuidar y conservar la cosa sana y útil; pero si ya la entrega se ha efectuado, es el comprador quien debe demostrar que los vicios posteriores a ella tuvieron su origen en un momento anterior al contrato ${ }^{108}$. Me parece que esta propuesta no es de recibo, y además no existe fundamento normativo para sostenerla, por lo cual considero que es la primera posición la que debe admitirse. Además, si se trata de defectos que aparecen después de la celebración del contrato y antes de la entrega, corresponde más bien a una posible situación de incumplimiento de la obligación de conservar y custodiar el bien, pero no de vicios ocultos ${ }^{\mathrm{IO}}$.

Se puede asumir entonces que, en materia probatoria, es al comprador a quien corresponde demostrar la existencia del vicio, su anterioridad con respecto al contrato y su carácter grave, al impedir o disminuir la utilidad del bien; aspecto este último en el que deberá tenerse en cuenta tanto un criterio subjetivo -referido a la finalidad para la cual adquirió el bien- como uno objetivo -el uso normal-, que viene a ser residual frente al primero, es decir, se considera solo cuando las partes no identifican las cualidades o fines particulares a los que deba servir el bien según sus intereses de contratación; cuando estas no se puedan deducir implícitas, no se alegare un uso especialmente pactado o no pudiera demostrarse, se atenderá de forma subsidiaria al criterio del tráfico o "usos normales", que son asumidos como los queridos implícitamente por los contratantes ${ }^{\text {IIO }}$. En caso de no coincidir el criterio objetivo con el subjetivo, debe prevalecer este último, al tener en consideración que fue lo que motivó al comprador a celebrar el contrato ${ }^{\mathrm{II}}$.

io7 Cfr. Bonivento Fernández, ob. cit., i44. Cárdenas Mejía, ob. cit., 227 y 234. Rodríguez FonNeGRa, ob. cit., 877 .

IO8 Pérez Vives, ob. cit., n. ${ }^{\circ} 340,38$ o.

iog Cfr. Cárdenas Mejía, ob. cit., 227.

i ro Díez-Picazo, L., Fundamentos del Derecho Civil patrimonial. Iv. Las particulares relaciones obligatorias, Civitas, Thomson Reuters, Elcano, 20 IO, I37. Morales Moreno, "El alcance protector de las acciones edilicias", cit., 635. Orti Vallejo, ob. cit., 227. Verda y Beamonte, ob. cit., 85. Véase sobre estos criterios, con base en fallos del Tribunal Supremo español, Fenoy Picón, N., Falta de conformidad e incumplimiento en la compraventa. (Evolución del ordenamiento español), Colegio de Registradores de la Propiedad y Mercantiles de España. Centro de Estudios Registrales, Madrid, I996, I 85 a I 87 . En la doctrina francesa, HuEt, Responsabilité du vendeur, cit., I63 a I65. HuEt, Les principaux contrats spéciaux, cit., n. ${ }^{\circ}$ I I 3 18, 277.

i I I Según menciona Fenoy, este es el criterio que ha adoptado el Tribunal Supremo español en sentencia del 3i de enero de i97I. Cfr. Fenoy Picón, ob. cit., I86-i87. 


\section{Conclusiones}

Además de lo expuesto puntualmente en este artículo, se pueden inferir como principales conclusiones las siguientes:

I. Los requisitos de gravedad del vicio, de anterioridad al contrato (o a la entrega, según el caso) y de ser oculto son concurrentes, en el sentido en que deben verificarse los tres. Si alguno fallare, no procede el saneamiento, aunque de todas formas el Código Civil chileno-colombiano permite al comprador obtener una rebaja de precio en los casos en que los vicios no sean graves.

2. El carácter del vicio de ser anterior al contrato exigido por las normas civiles corresponde al momento de transmisión del riesgo por pérdida fortuita del bien, de tal modo que desde la celebración del contrato el comprador corre con la suerte de la cosa comprada. No ocurre lo mismo en las ventas de género, en las que tanto el momento de traslación de riesgos como el de asunción de los vicios ocultos es el mismo de la identificación del bien.

3. El requisito de gravedad se refiere a la manera como el vicio compromete la idoneidad del bien, y debe ser de tal magnitud que impida o reduzca de modo considerable el uso normal o pactado, lo que permite distinguir entre vicio grave, menos grave y el defecto que no es vicio. La relevancia del vicio manifestada en la mayor o menor gravedad exige ser analizada en el caso concreto, excluyendo sólo los defectos que desagradan al comprador pero que no comprometen el uso del bien, de lo que deducimos que el carácter de gravedad es relativo.

4. El Código Civil chileno-colombiano permite la alternativa de la acción redhibitoria o de la rebaja de precio, a escogencia del comprador, para cuando el vicio tenga la relevancia mencionada. Cuando no sea grave, permite sólo la rebaja de precio, como una forma de aplicar el principio de conservación del contrato.

5. El carácter oculto del bien es relativo, al tener en consideración no sólo que el vendedor no lo haya manifestado, sino también las circunstancias particulares del comprador y el hecho de ser tal que este no haya podido ignorarlo sin incurrir en culpa grave; lo que exige, según las normas y la interpretación jurisprudencial vigente, una diligencia mínima de su parte, consistente en revisar el bien, de forma que si a simple vista no aparece el vicio, es oculto. A diferencia de lo anterior, si el comprador fuere un profesional se exige una diligencia mayor que simplemente observar el bien, de manera que deberá probarlo, ensayarlo o asesorarse de expertos para detectar la eventual presencia del vicio. 


\section{Bibliografía}

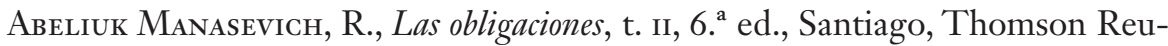
ters-La Ley, 2014.

Aguayo, J., Las manifestaciones y garantías en el Derecho de contratos español, Pamplona, Civitas-Thomson Reuters, 20 I I.

Alessandri Rodríguez, A., De la compra-venta i de la promesa de venta, t. II, Santiago, Imprenta litográfica Barcelona, ı9ı8.

Alter, M., L'obligation de délivrance dans la vente de meubles corporels, París, LGDJ, I972.

Badenes Gasset, R., El contrato de compraventa, t. I, 3. ${ }^{a}$ ed., Barcelona, José María Bosch, I995.

Baudry-Lacantinerie, G. y Saignat, L., Traité théorique et pratique de Droit Civil. De la vente et de l'échange, XIX, $3 \cdot{ }^{\mathrm{a}} \mathrm{ed}$., Paris, Librairie de la société du Recueil J. B. Sirey et du Journal du Palais, I9o8.

Bénabent, A., Droit civil. Les contrats spéciaux civils et commerciaux, 9. ${ }^{a}$ ed., Paris, Montcherestien Lextenso, 20 I I.

Bianca, C. M., "La vendita e la permuta", en Trattato di Diritto civile italiano, fondato da Filippo Vassalli, v. 7, t. I, 2. ${ }^{a}$ ed., Torino, Utet, I 993.

Bonivento Fernández, J. A., Los principales contratos civiles y su paralelo con los comerciales, I 7. a ed., Bogotá, Librería Ediciones del Profesional, 2008.

Borda, G., Tratado de Derecho Civil, Contratos, t. I, 8. ${ }^{a}$ ed. actualizada con la colaboración de Alejandro Borda, Buenos Aires, Lexis Nexis-Abeledo Perrot, 2005 .

Borrell y Soler, A., El contrato de compraventa según el Código Civil español, Barcelona, Bosch, I952.

Cárdenas Mejía, J. P., "La resolución por problemas de funcionamiento de la cosa en el derecho colombiano: el régimen interno -vicios ocultos y garantía mínima presunta - y el régimen de la compraventa internacional de mercaderías", en La terminación del contrato. Nuevas tendencias del Derecho comparado, 
José Alberto Gaitán Martínez y Fabricio Mantilla Espinosa (dirs.), Bogotá, Universidad del Rosario, 2007, 2 I 7-3 I6.

Collart Dutilleul, F. y Delebecque, Ph., Contrats civils et commerciaux, 8. a ed., Paris, Dalloz, 2007.

Cottin, E., La définition du vice caché dans la vente. Étude de Droit comparé, París, LGDJ, I940.

de Elizalde Ibarbia, F., El contenido del contrato, Cizur Menor, Thomson Reuters, 2015 .

Díez-Picazo, L., Fundamentos del Derecho Civil patrimonial. I. Introducción. Teoría del contrato, 6. ${ }^{\mathrm{a}}$ ed., Cizur Menor, Thomson Civitas, 2007.

Díez-Picazo, L., Fundamentos del Derecho Civil patrimonial. IV. Las particulares relaciones obligatorias, Civitas, Elcano, Thomson Reuters, 20 Iо.

Domat, J., Les loix civiles dans leur ordre naturale, t. I, Paris, Chez Nyon Ainé Libraire, I 777 .

Fenoy Picón, N., Falta de conformidad e incumplimiento en la compraventa. (Evolución del ordenamiento español), Colegio de Registradores de la Propiedad y Mercantiles de España. Madrid, Centro de Estudios Registrales, I996.

Gross, B. у Bıнr, Рн., Contrats. Ventes civiles et commerciales, baux d'babitation, baux commerciaux, 2. éd., Paris, Presses Universitarires de France, 2002.

Herbosa Martínez, I., El contrato de compraventa civil, Cizur Menor, CivitasThomson Reuters, 20I3.

Huet, J., Responsabilité du vendeur et garantie contre les vices cachés, Paris, Litec, I987.

Huet, J., "Les principaux contrats spéciaux", en Traité de Droit Civil sous la direction de Facques Ghestin, 2. ${ }^{\text {a }}$ ed., Paris, LGDJ, $200 \mathrm{I}$.

García Pérez, C. L., "Artículo i 484", en Comentarios al Código Civil, t. vir (arts. I 265 a I484), Bercovitz Rodríguez-Cano, Rodrígo (dir.), Valencia, Tirant lo Blanch, 2013, I05 I 7-I0534. 
Ghestin, J., Conformité et garanties dans la vente (Produits mobiliers), París, LGDJ, I 983 .

Gómez Estrada, C., De los principales contratos civiles, 4. ${ }^{\text {a }}$ ed., Bogotá, Temis, 2008.

Gómez Mejía, J. A., Contratos comerciales, Bogotá, Editorial Kelly, ı980.

Grassi, U., I vizi della cosa venduta nella dottrina dell'errore. Il problema dell'inesatto adempimento, Napoli, Edizioni Scientifiche Italiane, 1996.

Greco, P. y Cottino, G., Vendita, Commentario del Codice Civile a cura di A. SCIA-

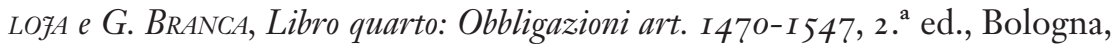
Zanichelli, I98 I.

Gross, B. y Bıнr, Pн., Contrats. Ventes civiles et commerciales, baux d'habitation, baux commerciaux, 2. éd., Paris, Presses Universitarires de France, 2002.

Huet, J., Responsabilité du vendeur et garantie contre les vices cachés, Paris, Litec, I 987 .

Le Tourneau, Ph., "Conformités et garanties dans la vente d'objets mobiliers corporels", en RTD Com., t. xxxIII, (I980), 23 I-276.

Le Tourneau, Ph., Responsabilité des vendeurs et fabricants, $4 \cdot{ }^{\mathrm{a}}$ ed., Paris, Dalloz, 2 OII.

Le Tourneau, Ph., Droit de la responsabilité et des contrats, 9. ${ }^{a}$ ed., Paris, Dalloz, $2 O I 2$.

Llamas Ромво, Eugenio, La compraventa, Madrid, La Ley, 20 i4.

Luminoso, A., La compravendita, sesta edizione, Torino, Giappichelli, 2009.

Malaurie, Ph., Aynès, L. y Gautier, P.-Y., Les contrats spéciaux, en Droit Civil, Malaurie, P.; Aynès, L., 4. ${ }^{\text {a }}$ ed., Paris, Defrénois, Lextenso éditions, 2009.

Miquel, S., "Responsabilidad por vicios redhibitorios en los contratos civiles, comerciales y de consumo", en Derecho de los contratos. Técnica de la contratación actual. Libro en homenaje a la escribana Beatriz A. Maury, Buenos Aires, Ad-Hoc, 2008, I49-20I. 
Morales Moreno, A. M., "El alcance protector de las acciones edilicias", Anuario de Derecho Civil, t. xxxıI, f. III, (I980), 585-686.

Morales Moreno, A. M., "Artículo i484", en Comentario del Código Civil, v. iI, Paz-Ares Rodríguez, C.; Bercovitz, R.; Díez-Picazo Ponce de León, L. y Salvador Coderch, P. (dirs.), Madrid, Ministerio de Justicia, i 99 I, 953-957.

Orti Vallejo, A., La protección del comprador por el defecto de la cosa vendida, Granada, Ediciones TAT, 1987.

Oviedo Albán, J., La garantía por vicios ocultos en la compraventa. Análisis de Derecho Privado chileno y colombiano a la luz de las nuevas tendencias del Derecho de contratos, tesis doctoral, Santiago, Universidad de los Andes, 2012.

Oviedo Albán, J., "Sobre el concepto de vicio redhibitorio en la compraventa. Análisis comparado de la jurisprudencia chilena y colombiana", Revista Chilena de Derecho, v. 37, n. ${ }^{\circ}$, (2010), 24I-269.

Oviedo Albán, J., La garantía por vicios ocultos en la compraventa. Análisis de Derecho Privado chileno y colombiano a la luz de las nuevas tendencias del Derecho de contratos, tesis doctoral, Santiago, Universidad de los Andes, 20 I 2.

Pérez Vives, Á., Compraventa y permuta en Derecho colombiano, 2. a ed., Bogotá, Temis, I953.

Planiol, M. y Ripert, G., Tratado práctico de Derecho Civil francés, t. vi, Las obligaciones, primera parte, traducción española de Mario díaz Cruz con la colaboración de Eduardo Le Riverend Brusone, La Habana, Cultural S. A., I 946.

Rengifo, R., Contratos comerciales, v. I, La compraventa mercantil, el transporte, el suministro, 2. ${ }^{\mathrm{a}}$ ed., Colección Pequeño Foro, Medellín, I98 I.

Rodríguez Fonnegra, J., De la compraventa y materias aledañas, Bogotá, Lerner, I960.

Roppo, V., "Il contratto", en Trattato di Diritto Privato a cura di Giovanni Iudica e Paolo Zatti, Milano, Giuffrè, $200 \mathrm{I}$.

Rubino, D., "La compravendita”, en Trattato di Diritto Civile e Commerciale diretto dai professori Antonio Cicu; Francesco Messineo, v. xxıI, Milano, Giuffrè, I97 I. 
Serrano Chamorro, M. E., Entrega de cosa distinta a la pactada, Cizur Menor, Thomson Aranzadi, 2006.

Spota, A. G., Instituciones de Derecho Civil. Contratos, v. Ix, Buenos Aires, Depalma, I984.

Tamayo Lombana, A., El contrato de compraventa, su régimen civil y comercial, Bogotá, Ediciones Doctrina y Ley Ltda., 2004.

Valencia Zea, A., Derecho Civil, t. iv, De los contratos, 6. a ed., Bogotá, Temis, i 985.

Vélez, F., Estudio sobre el Derecho Civil colombiano, t. vII, 2. ${ }^{a}$ ed., corregida y aumentada por Luis Ángel Arango, París, Imprenta París-América, i926.

Verda y Beamonte, J. R. de, Saneamiento por vicios ocultos. Las acciones edilicias, 2. a ed., Cizur Menor, Aranzadi, 2009.

Vidal Olivares, Á., La protección del comprador. Régimen de la Convención de Viena y su contraste con el Código Civil, Valparaíso, Ediciones Universitarias de Valparaíso, Pontificia Universidad Católica de Valparaíso, 2006.

Vidal Olivares, Á., "El incumplimiento de obligaciones con objeto fungible y los remedios del acreedor afectado. Una relectura de las disposiciones del "Código Civil" sobre incumplimiento", en El Código Civil de Chile (I8552005). Trabajos expuestos en el congreso internacional celebrado para conmemorar su promulgación (Santiago, 2-6 de octubre de 2005), Guzmán Brito, A. (ed. científico), 2. ${ }^{\text {a }}$ ed., Santiago, Legal Publishing, 2009, 495-55०.

Wayar, E., Evicción y vicios redhibitorios, 2, Buenos Aires, Astrea, I992.

\section{Jurisprudencia}

\section{Chile:}

Corte de Santiago, 25 de julio de i88 i, G. i 88 i, n. ${ }^{\circ}$ i.2 $78,762$.

Corte de Santiago, 2 I de junio de i882, G. i 882, n. ${ }^{\circ}$ I 257,73 I.

Corte de Santiago, ig de agosto de i 884, G. i 884, n. ${ }^{\circ} 2030$, i 244.

Corte de Santiago, i de octubre de i 884, n. ${ }^{\circ} 2495$, G. i 884 , i 569. 
Corte de Valparaíso, 22 de octubre de i9oo, G. i90o, t. 2, n. ${ }^{o}$ i 794, 832.

Corte de Santiago, i9 de marzo de i932, RdJ, t. 29, secc. 2. a 78.

Corte Suprema, i i de abril de 2002, Rol 986 - 200I, n. ${ }^{\circ}$ Legal Publishing: 24 I 68.

Corte Suprema, i 8 de enero de 20 i i, causa n. ${ }^{\circ} 32$ I 6/2009, resolución n. ${ }^{\circ} 2775$,

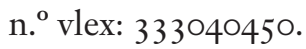

Corte de Apelaciones de Concepción, in de agosto de 20 i , Causa n. ${ }^{\circ}$ 7I6/20 I I, resolución n. ${ }^{\circ} 39058$, n. ${ }^{\circ}$ vlex: 3 I 30006 I4.

Corte Suprema, io de enero de 20 i 2, Rol i i924, mJj30693.

Corte de Apelaciones de Santiago, i6 de marzo de 20i2, Rol 7600-20io, n. ${ }^{\circ}$ Legal Publishing: CL/JUR/62 I/20 2.

Corte Suprema. Corte Suprema, 4 de octubre de 2012 , Rol 3740 - 201 2, n. ${ }^{\circ}$ Legal Publishing: CL/JUR/2 I 86/20 2.

Corte de Apelaciones de Santiago, 7 de noviembre de 20i 2, Rol 3 i 8 - 20 i 2 , n. ${ }^{\circ}$ Legal Publishing: CL/JUR/2634/201 2 .

\section{Colombia:}

Corte Suprema de Justicia, 5 de julio de i 899, G.J., Xiv, núms. 7 I 3 y 7 I 4, 282.

Corte Suprema de Justicia, Sala de Casación Civil, i 5 de octubre de i968, M.P. Guillermo Ospina Fernández, (sin publicar en la Gaceta Judicial).

Corte Suprema de Justicia, Sala de Casación Civil, 6 de marzo de i 945, M.P. Fulgencio Lequerica Vélez, G.J., LVIII, 638.

Corte Suprema de Justicia, Sala de Casación Civil, 23 de junio de i955, M.P. Agustín Ariza Prada, G.J., t. Lxxx, n. ${ }^{\circ} 2$ I 53, $45^{2}$.

Corte Suprema de Justicia, Sala de Casación Civil, i 5 de octubre de i968, M.P. Guillermo Ospina Fernández, (sin publicar en la Gaceta Judicial).

Corte Suprema de Justicia, Sala de Casación Civil, 25 de marzo de i969, M.P. Enrique López de la Pava, G.J., t. cxxix, núms. 2306, 2307 y 2308, Io. 
Corte Suprema de Justicia, Sala de Casación Civil, i i de octubre de i977, M.P. Germán Giraldo Zuluaga, (sin publicar en la Gaceta Judicial).

Corte Suprema de Justicia, Sala de Casación Civil, 9 de agosto de i 993, M.P. Rafael Romero Sierra, exp. 3727, G.J., ccxxv, n. ${ }^{\circ}, 2464$, p. 3 I4.

Corte Suprema de Justicia, Sala de Casación Civil, i4 de enero de 2005, M.P. Edgardo Villamil Portilla, exp. 7524, en DVD - Rom, Colección Furisprudencial en DVD, RSJ, Bogotá, 2009.

Corte Suprema de Justicia, Sala de Casación Civil, M.P. Pedro Octavio Munar Cadena, 6 de agosto de 2007, exp. I300 I 3 I 03 O0 I I999 00 57 O I, en Notinet. 